Al1106 977904

PUBLICATIONS

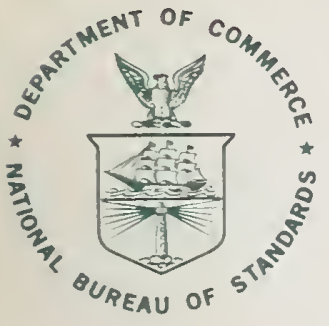

NBS SPECIAL PUBLICATION 400-71

U.S. DEPARTMENT OF COMMERCE / National Bureau of Standards

Semiconductor Measurement Technology:

\title{
Differential Capacitance-Voltage Profiling of Schottky Barrier Diodes for Measuring Implanted Depth Distributions in SHlicon
}

$-O C$

100

.057

$10.400-71$

1902

C.? 


\section{NATIONAL BUREAU OF STANDARDS}

The National Bureau of Standards' was established by an act of Congress on March 3, 1901. The Bureau's overall goal is to strengthen and advance the Nation's science and technology and facilitate their effective application for public benefit. To this end, the Bureau conducts research and provides: (1) a basis for the Nation's physical measurement system, (2) scientitic and technological services for industry and government, (3) a technical basis for equity in trade, and (4) technical services to promote public safety. The Bureau's technical work is performed by the National Measurement Laboratory, the National Engineering Laboratory, and the Institute for Computer Sciences and Technology.

THE NATIONAL MEASUREMENT LABORATORY provides the national system of physical and chemical and materials measurement; coordinates the system with measurement systems of other nations and fürnishes essential services leading to accurate and uniform physical and chemical measurement throughout the Nation's scientific community, industry, and commerce; conducts materials research leading to improved methods of measurement, standards, and data on the properties of materials needed by industry, commerce, educational institutions, and Government; provides advisory and research services to other Government agencies; develops, produces, and distributes Standard Reference Materials; and provides calibration services. The Laboratory consists of the following centers:

Absolute Physical Quantities ${ }^{2}$ - Radiation Research - Thermodynamics and -

Molecular Science - Analytical Chemistry - Materials Science.

THE NATIONAL ENGINEERING LABORATORY provides technology and technical services to the public and private sectors to address national needs and to solve national problems; conducts research in engineering and applied science in support of these efforts; builds and maintains competence in the necessary disciplines required to carry out this research and technical service; develops engineering data and measurement capabilities; provides engineering measurement traceability services; develops test methods and proposes engineering standards and code changes; develops and proposes new engineering practices; and develops and improves mechanisms to transfer results of its research to the ultimate user. The Laboratory consists of the following centers:

Applied Mathematics - Electronics and Electrical Engineering ${ }^{2}$ - Mechanical

Engineering and Process Technology ${ }^{2}$ - Building Technology — Fire Research -

Consumer Product Technology - Field Methods.

THE INSTITUTE FOR COMPUTER SCIENCES AND TECHNOLOGY conducts research and provides scientific and technical services to aid Federal agencies in the selection, acquisition, application, and use of computer technology to improve effectiveness and economy in Government operations in accordance with Public Law 89-306 (40 U.S.C. 759), relevant Executive Orders, and other directives; carries out this mission by managing the Federal Information Processing Standards Program, developing Federal ADP standards guidelines, and managing Federal participation in ADP voluntary standardization activities; provides scientific and technological advisory services and assistance to Federal agencies; and provides the technical foundation for computer-related policies of the Federal Government. The Institute consists of the following centers:

\section{Programming Science and Technology-Computer Systems Engineering.}

'Headquarters and Laboratories at Gaithersburg, MD, unless otherwise noted;

mailing address Washington, DC 20234.

${ }^{2}$ Some divisions within the center are located at Boulder, CO 80303. 


\section{Differential Capacitance-Voltage Profiling of Schottky Barrier Diodes for Measuring Implanted Depth Distributions in Silicon}

\section{R. G. Wilson and D. M. Jamba}

Hughes Research Laboratories

3011 Malibu Canyon Road

Malibu, CA 90265

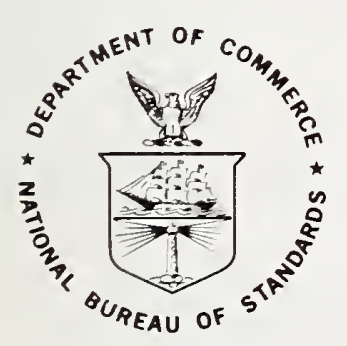

U.S. DEPARTMENT OF COMMERCE, Malcolm Baldrige, Secretary NATIONAL BUREAU OF STANDARDS, Ernest Ambler, Director 


\section{Library of Congress Catalog Card Number: 81-600162}

National Bureau of Standards Special Publication 400-71

Nat. Bur. Stand. (U.S.), Spec. Publ. 400-71, 58 pages (Feb. 1982)

CODEN: XNBSAV 
Abstract . . . . . . . . . . . . . . . . . . . . . . . 1

1. Introduction . . . . . . . . . . . . . . . . . . . . . 1

1.1 The Purpose and Application . . . . . . . . . . . . . . 1

1.2 Ion-Implanted Depth Distributions . . . . . . . . . . . . . 2

1.3 Ranges of Application and Limitations . . . . . . . . . . . 3

2. Differential $\mathrm{C}-\mathrm{V}$ Profiling . . . . . . . . . . . . . . . 4

2. 1 The Technique . . . . . . . . . . . . . . . . . . . . . 4

2.2 The Procedure . . . . . . . . . . . . . . . . . . . . 9

2.3 Profiler Circuit Analysis . . . . . . . . . . . . . . . 10

2.3.1 Frequency . . . . . . . . . . . . . . . . . . . . 12

2.3.2 Influence of Diode Size... . . . . . . . . . . . . . 13

2.3.3 Influence of Substrate Resistivity . . . . . . . . . . . 13

2.3.4 Error Analysis . . . . . . . . . . . . . . . . . . 14

2.3.5 Phase Error . . . . . . . . . . . . . . . . . 14

2.3.6 Voltage Sweep Rate .................... . . 18

2.3.7 Ambient Light Intensity . . . . . . . . . . . . . . . . . 18

2.3.8 Cable Compensation and Zero Calibration . . . . . . . . . . 23

2.3.9 Experimental Errors . . . . . . . . . . . . . . . . . 23

2.4 Summary . . . . . . . . . . . . . . . . . . . . . 23

3. Schottky Barriers . . . . . . . . . . . . . . . . . . . 24

3.1 Introduction . . . . . . . . . . . . . . . . . . . . 24

3.2 Metals for Schottky-Barrier Formation on p-Type and n-Type Silicon 25

3.3 Schottky Barrier Height Measurement and Aging . . . . . . . . . . . 28

3.4 Schottky Barrier Area and Quality Measurement Techniques • . . . 28

3.5 Attempts to Improve $\mathrm{C}-\mathrm{V}$ Profiles of Schottky Barriers . . . . . . 31

3.6 summary . . . . . . . . . . . . . . . . . 34

4. Sample Preparation, Implantation, and Processing . . . . . . . 37

4.1 Summary . . . . . . . . . . . . . . . . . . . . 37

4.2 Material . . . . . . . . . . . . . . . . . 38

5. Data Analyses . . . . . . . . . . . . . . . . . 38

5.1 The Kennedy-O'Brien Correction . . . . . . . . . . . . . 38

5.2 Background Subtraction . . . . . . . . . . . . . . . . . 41

6. Comparisons of $\mathrm{C}-\mathrm{V}$ and SIMS Profiles . . . . . . . . . . . . 42

6.1 The SIMS Technique and Experimental Accuracies . . . . . . . . 42

6.1.1 Experimental Errors . . . . . . . . . . . . . . . . 4 42

6.2 Comparison of SIMS Atom and C-V Carrier Distributions . . . . . . 43

7. Conclusions and Summary . . . . . . . . . . . . . . . . 45

7.1 What Can Be Measured by Differential C-V Profiling . . . . . . . 47

7.2 Limitations on the $\mathrm{C}-\mathrm{V}$ Profiling Technique . . . . . . . . . . . 47

References . . . . . . . . . . . . . . . . . . . 4 48 
1. Diode confiqurations for $\mathrm{C}-\mathrm{V}$ profiling . . . . . . . . . . . . 8

2. Parallel equivalent circuit . . . . . . . . . . . . . . . 11

3. Series equivalent circuit seen by capacitance meter . . . . . . . . 11

4. A C $-V$ profile that shows the nature of an error caused by a high sample capacitance . . . . . . . . . . . . . . . 15

5. Two $\mathrm{C}-\mathrm{V}$ profiles that show the nature of an error caused by using a sample area that is too large . . . . . . . . . . . . . . 16

6. Several $\mathrm{C}-\mathrm{V}$ profiles that show the nature of the loss of data caused by voltage breakdown . . . . . . . . . . . . . . . 17

7. C-V profiles for a silicon specimen implanted with 300-keV boron

for various voltage sweep rates shown in the inset . . . . . . .

8a. C-V profiles for varying light intensity environments; aluminum Schottky barrier . . . . . . . . . . . . . . . . .

8b. C-V profiles for varying light intensity environments; titaniumgold schottky barrier . . . . . . . . . . . . . . . .

8C. C-V profiles for varying light intensity environments; molybdenumgold Schottky barrier . . . . . . . . . . . . . . . . 22

9. C-V profiles and Schottky barrier data for four metallization systems on p-type, $\sim 100 \Omega \cdot \mathrm{cm}$ implanted silicon surfaces . . . . . 26

10. C-V profiles and Schottky barrier data for four metallization systems on $n$-type, $\sim 100 \Omega \cdot \mathrm{cm}$ implanted silicon surfaces . . . . .

11. Plots of $\mathrm{C}^{-2}-\mathrm{V}$ Schottky barrier height determination; aluminum on p-type silicon . . . . . . . . . . . . . . . . . . .

12. Plots of $\mathrm{C}^{-2}-\mathrm{V}$ Schottky barrier height determination; gold on $n-$ type silicon . . . . . . . . . . . . . . . . . . . . .

13. Typical I-V characteristics for Schottky barriers on $p$ - and n-type ion-implanted silicon surfaces . . . . . . . . . . . . . . .

14. Capacitance values for good $C-V$ profiles of varying depth . . . .

15. Typical deep $\mathrm{C}-\mathrm{V}$ profiles showing effects of Kennedy-O'Brien correction and of correction for substrate dopant level . . . . .

16. Typical shallow $\mathrm{C}-\mathrm{V}$ profiles showing effects of Kennedy-O'Brien correction and of correction for substrate dopant level . . . . . . 40

17. SIMS and $\mathrm{C}-\mathrm{V}$ profiles for $100 \mathrm{keV}$ beryllium in silicon . . . . . . 44

18. SIMS and $\mathrm{C}-\mathrm{V}$ profiles for $300-\mathrm{keV}$ boron in silicon . . . . . . . 46 
This study was carried out at the Hughes Research Laboratories (HRL) as a part of the Semiconductor Technology Program at the National Bureau of Standards. The Semiconductor Technology Program serves to focus NBS efforts to enhance the performance, interchangeability, and reliability of discrete semiconductor devices and integrated circuits through improvements in measurement technology for use in specifying materials and devices in national and international commerce and for use by industry in controlling device fabrication processes. The work was supported by the Defense Advanced Research Projects Agency, ARPA Order 2397, Program Code 6D10, through the National Bureau of Standards' Semiconductor Technology Program, Contract 535891. This contract was monitored by Dr. Kenneth F. Galloway as the Contracting officer's Technical Representative. Drs. W. M. Bullis, K. F. Galloway, and D. R. Myers provided technical review of this report for the National Bureau of Standards.

The authors wish to acknowledge helpful discussions with Drs. C. L. Anderson and $\mathrm{H}$. L. Stover of $\mathrm{HRL}$ concerning the analysis of $\mathrm{C}-\mathrm{V}$ profiling circuitry. They are especially grateful to Dr. James Comas of the Naval Research Laboratories for obtaining the SIMS atomic depth distributions used in section 6 for comparisons with the $\mathrm{C}-\mathrm{V}$ electrical depth distributions. 

Semiconductor Measurement Technology:

Differential Capacitance-Voltage Profiling of Schottky Barrier Diodes For Measuring Implanted Depth Distributions in Silicon

by

R.G. Wilson and D.M. Jamba

Hughes Research Laboratories

Malibu, CA 90265

This report discusses experimental and analytical aspects of differential capacitance-voltage profiling of ion-implanted carrier depth distributions using reverse-biased Schottky barrier diodes and the associated accuracies, experimental errors, and ranges of applicability.

Key words: automatic C-V profiler analyses; carrier depth distributions; differential capacitance-voltage profiling; ion implantation; ranges of application and limitations; Schottky barrier diodes; SIMS and C-V profile comparisons.

\section{INTRODUCTION}

1.1 The Purpose and Application

The general purpose of this report is to provide practical information and experimental data that will aid in the accurate design and fabrication of ion-implanted dopant profiles. Implantation is often utilized because it is known to be capable of greater control of dopant profiles than other dopant techniques. This potential superiority of implantation is lost in the practical world of device and circuit fabrication unless adequate knowledge and control of the range and shape of the implanted ion depth distribution and the factors that influence them are available. Knowledge of these factors and their application by the semiconductor device and integrated circuit industry should lead to increased production yield, field reliability, and device performance through the greater accuracy and tighter specifications that can be held through the use of the implantation dopant process.

The specific goal of the work described in this report was to establish controlled and reproducible schottky barrier diode and differential capacitance-voltage profiling technologies for measuring depth distributions or profiles of $p$ - and n-type ion-implanted layers in silicon. Differential capacitance-voltage $(\mathrm{C}-\mathrm{V})$ profiling measures the depth distribution of carriers (electrons or holes) in a semiconductor in the carrier density range from $10^{13}$ to $10^{18} \mathrm{~cm}^{-3}$. One application for which it is useful is the measurement of depth distributions of carriers resulting from ion implantation of semiconductors where the ion fluence or dose is less than about $10^{13} \mathrm{~cm}^{-2}$. 
The capacitance-voltage and capacitance-frequency behavior of semiconductor devices can be used in the evaluation of material purity, impurity density and depth distributions, interface-state and deep-level impurity densities and response times, insulator purity and thickness, and insulator effects on surface behavior of semiconductor devices. Differential $\mathrm{C}-\mathrm{V}$ measurements of reverse-biased diodes can be used to determine the presence of electrically active carriers and to plot their density profiles. This technique measures directly the density of carriers without requiring associated mobility measurements and corrections for varying mobility. The technique is applicable to compound semiconductors, for which controlled layer removal (stripping) is difficult.

The differential $\mathrm{C}-\mathrm{V}$ profiling technique and its accuracy and limitations have been described by a number of authors, including its originators, Thomas, Kahng, and Manz [1], and others [2-10]. Schottky diodes were used in this work because they provide a good approximation to the step junction model on which the equations for differential $\mathrm{C}-\mathrm{V}$ profiling are based; in fact, Amron [2] concludes that "whenever possible, Schottky diodes should be used..."

\subsection{Ion-Implanted Depth Distributions}

A treatment that has come to be known as the LSS theory after its developers [11] models the semiconductor host as a dense gas to represent an amorphous solid, and predicts a Gaussian depth distribution for implanted atoms, characterized by a projected mean depth or range $R_{p}$ and a characteristic width or standard deviation $\sigma$ or range straggle $\Delta R_{p}$, defined as the halfwidth at $\mathrm{e}^{-1 / 2} \mathrm{~N}_{\max }$. Calculations of $\mathrm{R}_{\mathrm{p}}$ and $\Delta \mathrm{R}_{\mathrm{p}}$ have been made by many workers $[12-17]$.

The introduction of higher order moments into these statistical treatments can explain shapes that differ from the Gaussian distribution. An example of such a treatment is the Pearson IV used by Hofker [18], which considers a third moment called skewness $\left(\gamma_{1}\right)$ and a fourth moment called kurtosis $\left(\beta_{2}\right)$, the first and second moments being the average range or mode $\left(R_{m}\right.$ or $\mu$ ) and range straggle or standard deviation ( $\Delta R_{p}$ or $\left.\sigma\right)$, respectively. The calculated range $R_{p}$ may be greater than or less than the first moment depending upon whether the third moment is neqative or positive.

The LSS theory assumes the substrate to be amorphous. In practice, most semiconductor substrates that are implanted are crystalline rather than amorphous. Because of the crystalline nature of the substrate, experimentally measured depth distributions can be different from the calculated distribution. The crystalline substrate can be oriented so as to appear relatively amorphous or atomically random in the direction of the incident ions to best simulate the assumed amorphous condition of the LSS theory; this is the "random equivalent" orientation. However, in this socalled "random equivalent" orientation of the crystalline substrate, some ions can penetrate deeper than the calculated range $R_{p}$ to produce a "channeling tail" on the deep side of the depth distribution. The magnitude of this tail depends on the variables that occur in the expression for the critical angle for channeling $\psi_{C}[19]$, which are the ion and substrate masses, the ion energy, and the substrate lattice spacings. Its magnitude 
also depends on the degree of crystallinity or openness of the axial and planar channels of the substrate lattice which is also affected by the amount of accumulated damage that is produced by the prior implantation. Thus, the final distribution depends on the total ion fluence or dose, the tail being more significant for low fluences and becoming less significant as damage increases, until saturation occurs when the substrate becomes amorphous as a result of the implantation damage. The saturated magnitude of the tail remains as the ion fluence increases. "Amorphization fluences" vary with the mass of the ion from about $10^{14}$ to $10^{16} \mathrm{~cm}^{-2}$.

Ions can also be implanted along the open low-index directions of the semiconductor crystal, in which case the ions have a greater probability of being guided or channeled deeper into the crystal down the axial and planar channels. This effect occurs until the lattice is damaged enough by the ions that are not channeled to a deep range to be made amorphous in the implanted region, that is, when the axial channels become blocked. The amorphization fluence in these cases is higher (by a factor of $\sim 2$ to 5 ).

\subsection{Ranges of Application and Limitations}

The technique of differential $\mathrm{C}-\mathrm{V}$ profiling is applicable to most semiconductor materials. It is ideal for determining depth distributions for lower fluence implants, for measuring channeling tails on distributions in crystalline substrates, and for measuring channeled distributions. It is especially useful for studies where a large number of samples need to be examined or a large number of values of variables are required, because the sample processing is simple and the experimental measurement of the profile requires only a short time. It is much faster than the method of controlled layer removal (stripping) with Hall measurement of the carriers. The technique is useful for estimating the energy levels of deep acceptor or donor states of implanted species by estimating the shift in depth of the peaks of the implanted profiles $[20,21]$. This latter measurement requires the knowledge of the depth of the implanted atoms, for example, by an LSS range calculation. Thus, there may be some error associated with this measurement resulting from differences between calculated and actual ranges.

Kennedy and O'Brien [3] argue that differential C-V profiling measures the majority carrier distribution and this distribution may differ from that of the atom depth distribution. However, this effect is small for profiles deeper than about $0.5 \mu \mathrm{m}$ and causes only a small correction $(\sim 1$ to 5 percent in depth) to the $\mathrm{C}-\mathrm{V}$ profiles for densities below about $10^{15} \mathrm{~cm}^{-3}$, as shown in section 5.1 of this report and by Moline [4], Moline and Reutlinger [22], and Reddi and Sansbury [6], and by comparisons of $C-V$ carrier profiles and secondary-ion-mass spectroscopy (SIMS) atom profiles for samples implanted with the same or slightly different ion fluences. Evaluations of range, straggle, skewness, and kurtosis are made near the peak of the depth distribution, or above $\sim 10^{15} \mathrm{~cm}^{-3}$, and are little affected by the "KennedyO'Brien correction." The "Kennedy-O'Brien correction" does have an effect in the region of channeling tails on random equivalent implants in crystalline materials; the magnitude of the correction decreases with increasing depth of the profile (see sec. 5.1). 
The range of depth that can be measured by differential $C-V$ profilinq of Schottky barriers is about $0.08 \mu \mathrm{m}$ to $10 \mu \mathrm{m}$. These extremes cannot be measured in a single profile, however. A rule of thumb is that the depth distribution can extend over one order of magnitude in depth. For example, a distribution that extends to a depth of $0.8 \mu \mathrm{m}$ might give information to within $0.08 \mu \mathrm{m}$ of the surface, but a distribution that extends to $6 \mu \mathrm{m}$ would give data only to within about $0.6 \mu \mathrm{m}$ of the surface. The zero bias depletion depth, which is the controlling factor for the shallow side, varies with the depth of the charges and the density of the dopants (the profile itself). Depths of $0.08 \mu \mathrm{m}$ to $8 \mu \mathrm{m}$ are associated with the general range of ion energy from 10 to $1,000 \mathrm{keV}$, depending upon the mass of the implanted ion.

Effects of annealing temperature and implantation temperature can be followed by $\mathrm{C}-\mathrm{V}$ profiling. The technique is not useful for high ion fluences nor for ion species that do not produce carriers in the crystal.

A more widely applicable, but physically destructive, method for depth profiling electrical activity is the measurement of spreading resistance on beveled specimens. Spreading resistance and its comparison with $\mathrm{C}-\mathrm{V}$ and SIMS techniques are described by Albers et $a$. [23]

\section{DIFFERENTIAL $\mathrm{C}-\mathrm{V}$ PROFILING}

\subsection{The Technique}

The basic concept underlying all capacitance measurements of charge density in semiconductor devices is Poisson's equation, expressed in one dimension as :

$$
\frac{\mathrm{d}^{2} \mathrm{v}}{\mathrm{d} \mathrm{x}^{2}}=\frac{\rho(\mathrm{x}, \ldots)}{\varepsilon},
$$

where $x$ is the distance measured parallel to the applied electric field and $\rho, V$, and $\varepsilon$ are the total charge density, electrostatic potential, and permittivity, respectively, all measured at $x$. In general, $\rho$ may be a function of $x$, angular frequency $(\omega)$, temperature (T), and other variables. By measuring the dependence of $\rho$ on one or more of these parameters by capacitance measurements, it is possible to determine characteristics of the charge distribution in particular devices and implanted regions. For cases where the energy level of the impurity is such that not all of the impurities are ionized at ambient temperature, e.g., for indium in silicon at $300 \mathrm{~K}$, the applied voltage may ionize the remainder.

The device geometries most frequently evaluated by capacitance techniques are generally of two classes: (1) rectifying junction devices and (2) field effect devices [metal-oxide semiconductors (MOS) and metal-insulator semiconductors (MIS)]. The first class includes metal-semiconductor surface barrier (Schottky) diodes, one-sided (step) $p-n$ junctions where one side is heavily doped compared with the other, and multilayer junction devices. Schottky barrier diodes of $p^{+} n$ and $p n^{+}$junctions are frequently referred to as one-sided junctions because essentially all of the bias voltage drop 
occurs across the more lightly doped side of the junction. The second class includes MOS and MIS capacitors and other devices in which the field plates of the capacitor are separated by an essentially nonconducting layer. Because the information available from capacitance measurements for the two classes of devices is different, the two classes are treated separately.

In rectifying devices, the free carrier density $\mathrm{n}$ (at thermal equilibrium) can be obtained directly as a function of distance $\mathrm{x}$ from the junction by $\mathrm{C}-\mathrm{V}$ techniques. With the assumption of completely ionized impurities and an abrupt depletion region edge, the dopant density and depth relationships are:

$$
n(x)=\frac{C^{3}}{e \varepsilon A^{2} \frac{d C}{d V}}
$$

and

$$
x=\frac{\varepsilon A}{C}
$$

where $\mathrm{A}$ is the area of the device, and $\mathrm{x}$ is the depletion width or spacecharge region width. As the reverse-bias voltage $V$ is increased, the depletion width $\mathrm{x}$ increases, causing a decrease in capacitance. The area of junction $\mathrm{A}$ must be known well or a significant error can result in $\mathrm{n}(\mathrm{x})$. One advantage of $\mathrm{C}-\mathrm{V}$ profiling is that the probing $r f$ voltage can be on the order of $\mathrm{kT}(\sim 25 \mathrm{mV}$ at room temperature), thereby minimizing errors caused by rectification and diffusion capacitance at low reverse bias voltage. The quantity measured in eqs $(2 a)$ and $(2 b)$ is the carrier density. It is possible, however, to determine the ionized impurity density by further differentiation of the $\mathrm{C}-\mathrm{V}$ data. For completely ionized impurity species in nondegenerate n-type material, Poisson's equation is given by:

$$
\frac{d^{2} v}{d x^{2}}=\frac{e}{\varepsilon}\left[n(x)-n_{D}(x)\right] \text {, }
$$

where $n_{D}(x)$ is the donor density. Kennedy and O'Brien [3] show that:

$$
\frac{d^{2} V}{d x^{2}}=-\frac{d}{d x}\left[\frac{k T}{e} \frac{1}{n(x)} \frac{d n(x)}{d x}\right] \text {. }
$$

Substituting eq (4) into eq (3) and solving for $n_{D}(x)$ gives

$$
n_{D}(x)=n(x)+\frac{k T \varepsilon}{e^{2}} \frac{d}{d x}\left[\frac{1}{n(x)} \frac{d n(x)}{d x}\right] \text {. }
$$

This correction to obtain the dopant density from the measured carrier density is discussed in more detail in section 5.1 .

Capacitance-voltage data can be obtained using capacitance bridge measurements at a single high frequency (f $\sim 10^{5}$ to $10^{6} \mathrm{~Hz}$ ), while the applied bias is changed aperiodically at an average repetition rate of the 
order of 0.01 to $0.1 \mathrm{~Hz}$. The effect of deep impurities on such measurements is important. Impurities with response time slower than the periodic time of the high frequency signal affect the $\mathrm{C}-\mathrm{V}$ relationship by altering the static depletion layer width (because they can equilibrate with the bias changes), but do not alter the high frequency variation in the depletion layer width (because they cannot equilibrate with the high frequency). Measurements of the variation of the $C-V$ curves with frequency can yield information concerning the response times, energy levels, and densities of deep electrically active impurities $[24,20]$.

The capacitive behavior of MOS structures is more difficult to analyze than that of simple rectifying junction devices. However, a wealth of information can result from available analysis techniques. Capacitance-voltage measurements at a fixed frequency provide a method of determining fixed charge density in the insulator region, interface density, insulator thickness, and impurity density in the semiconductor region. Combined with capacitance measurements versus frequency at fixed biases, these measurements can be used to determine surface potential, standard deviation of surface potential, and interface state density and majority carrier cross section as a function of surface potential [25,26].

There are several reasons why profiling measurements by the bridge technique may not be desirable. First, most analyses involve differentiation of the capacitance data. The consequent loss of data can be severe, and potentially important effects can be entirely overlooked in such an analysis. Thus, continuous measurements are clearly desirable from a statistical point of view, if the measurement accuracy of the continuous method approaches that of a bridge technique. Secondly, the length of time required to perform the full set of measurements needed for a complete analysis is sufficient to make evaluation of a large number of samples prohibitive. Further, potentially important effects may be overlooked because of the unwieldiness of the bridge technique. For these reasons, automatic $\mathrm{C}-\mathrm{V}$ plotting instruments have been developed, particularly for the evaluation of impurity density versus distance in Schottky and junction devices, for example, the second harmonic method of Copeland [27]; the mixed frequency technique of Baxandall [28]; and the techniques of Gordon, Stover, and Harp [29]; Anderson, Baron, and Crowell [30]; and Miller [31]. The technique of Gordon et al. overcame many of the problems encountered with the rf harmonic techniques by utilizing the $1-\mathrm{kHz}$ ac signal directly, rather than the harmonic.

There are two general categories of sample preparation for $\mathrm{C}-\mathrm{V}$ profiling measurements in rectifying junction devices - Schottky barrier or junction. Schottky barriers create a better approximation to the step junction model, are more convenient, and are a nondestructive way to make contact. However, they may be leaky and may not always allow complete depletion of materials with high breakdown voltages. Interfacial effects at the metal-semiconductor junction can cause anomalous current-voltage ( $I-V$ ) and $C-V$ behavior. Fabrication of a $p-n$ junction requires more steps, but produces a diode with excellent leakage characteristics. For a Schottky barrier, a suitable metal such as titanium or aluminum is used on $p$-type silicon, or gold is used for n-type silicon and for gallium arsenide. The metal dots may be either evaporated through a mask or produced by photolithographic techniques. A $p-n$ 
junction can be formed by diffusion, ion implantation, or epitaxial growth of a $p$-layer on an n-region, followed by metallization and etching of a mesa junction. In either of the above procedures, a back ohmic contact is also prepared, for example, by implantation. During profiling, the $p-n$ junction is reverse biased and the depletion region extends toward the n-substrate. It is not necessary to fabricate a mesa in order to obtain profiling data. Buehler [32] has worked out corrections for a planar diode geometry. Before profiling, it is important to check the $I-V$ characteristics of the sample, to determine whether the device is leaky, and in the cases where avalanche breakdown occurs, what maximum voltage can be used to profile accurately.

For a junction device, a $\mathrm{C}-\mathrm{V}$ profile gives information near the junction and not necessarily near the peak of an implanted distribution. Profiles are usually measured in high resistivity or in lightly doped material (low implantation dose) to avoid avalanche breakdown. Surface effects, like inversion layers, can contribute to the capacitance and cause errors. Errors at lower dopant densities can result from the presence of significant free carrier distributions (see the discussion of the Kennedy-O'Brien correction, sec. 5.1). Charge neutrality in implanted semiconductors is discussed by Grimshaw and Osborne [33]. For $n^{+}$in $n$-or $p^{+}$in $p$-material, $C-V$ measurements may not distinguish between dopant species with shallow energy levels and other deep-level charge centers. The accuracy of the measurements can be verified by making DLTS or Hall measurements to determine the energy level of the dopant species. Another problem can be that heavily doped samples become inductive, making $\mathrm{C}-\mathrm{V}$ profiling invalid for heavily doped regions $\left(>\sim 10^{18}\right.$ $\mathrm{cm}^{-3}$ ). Limitations of the $\mathrm{C}-\mathrm{V}$ technique for ion-implanted profiles are discussed by Wu et al. [7], but most of their chosen analytical profiles are not encountered in careful $\mathrm{C}-\mathrm{V}$ profiling done within the region of validity of the techniques.

A differential $\mathrm{C}-\mathrm{V}$ profiler calculates the carrier distribution by measuring the equivalent capacitance $\mathrm{C}$ and changes in the capacitance with applied voltage $\mathrm{dC} / \mathrm{dV}$ of a reverse-biased diode. The area $\mathrm{A}$ of the diode must be measured independently and fed into the profiler which calculates (by analog or digital techniques) $\mathrm{n}(\mathrm{x})$ and $\mathrm{x}$ from the equations

$$
\begin{gathered}
n(x)=\frac{\left(c_{e q}\right)^{3}}{q \varepsilon A^{2}\left(\frac{d C}{d V}\right)}, \\
x=\frac{e A}{C_{e q}},
\end{gathered}
$$

as in eq (2), but where $\mathrm{C}_{\text {eq }}$ is the equivalent capacitance measured by the profiler which is related to the true diode capacitance $C_{S}$ as follows:

$$
c_{\text {eq }}=\frac{C_{s}}{\left[1+\left(\omega C_{s} R_{s}\right)^{2}\right]}=\frac{C_{s}}{\left(1+Q_{s}^{-2}\right)} \text {, }
$$


SCHOTTKY BARRIER DIODE (THIS WORK)

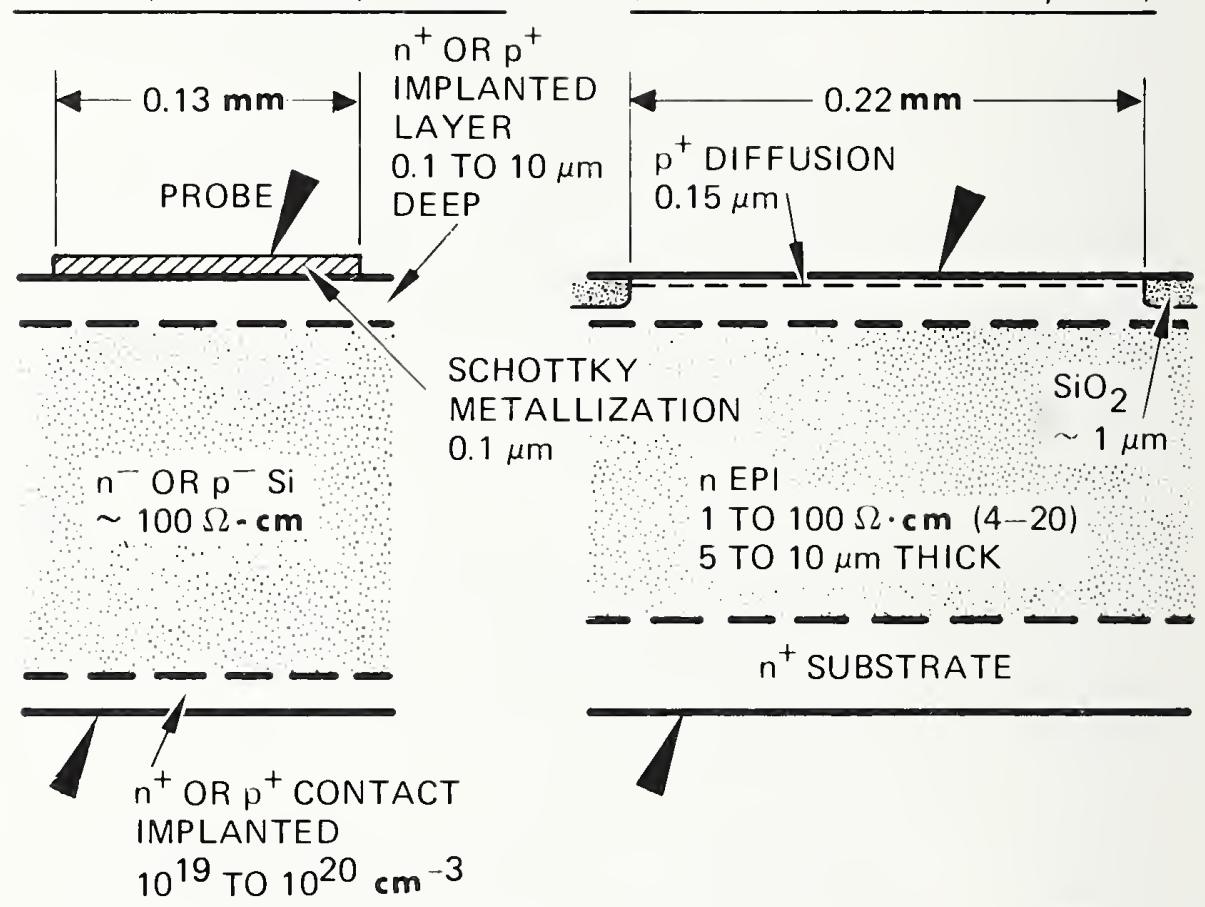

ADVANTAGES OF SCHOTTKY BARRIER:

PROFILE CLOSER TO SURFACE: LOWER ION ENERGY OR HIGHER Z

BOTH PEAK AND TAIL IN SAME PROFILE

Figure 1. Diode configurations for $\mathrm{C}-\mathrm{V}$ profiling. 
where $Q_{S}=\left(\omega C_{S} R_{S}\right)^{-1}$. In this expression, $\omega=2 \pi f$ where $f$ is the frequency of the profiler measuring circuit, $\mathrm{C}_{\mathrm{s}}$ is the true diode capacitance, and $R_{S}$ is the resistance of the diode. It is shown below that small diodes are required for good accuracy in differential C-V profiling.

Two diode configurations are illustrated in figure 1. As noted on the figure, two advantages of the Schottky barrier technique are the ability to measure the profile somewhat closer to the surface for shallow depth distributions ( $~ 80 \mathrm{~nm}$ versus $\sim 150 \mathrm{~nm}$ ), and to measure both the peak and the tail of a given distribution in the same profile, that is, with the same diode. Neither diode geometry will allow the profile to be measured close to the surface if the profile extends deeply into the substrate (e.g., greater than $1 \mu \mathrm{m})$. The Schottky barrier technique does not require correction for back depletion effects, see, e.g., [32].

This report discusses experimental work which used only the Schottky barrier technique; a description of use of the $p-n$ junction technique is given by Reddi and Sansbury [6]. In the work reported here, a vacuum hold-down applied to the reverse side of the silicon wafers provided good electrical contact to the reverse side of the samples, as well as mechanical stability during the measurements. A $25-\mu \mathrm{m}$ gold probe under compression provided the electrical contact to the 0.13- and 0.25-mm diameter Schottky barrier metallizations. For all samples studied, except for a few very deep implants, the $\mathrm{C}-\mathrm{V}$ profiles were obtained for reverse biases well below the avalanche breakdown voltages of the Schottky diodes, which varied from as high as $120 \mathrm{~V}$ for deeper implants to about $10 \mathrm{~V}$ for shallow implants. Photosensitivity of the Schottky diodes was checked frequently to ensure that no errors occurred in the depth profiles as a result of incident ambient light.

As Amron [2] points out, any underestimation of the geometric (measured) areas of the Schottky diodes (metallizations) causes the computed values of $n(x)$ and $x$ to be larger and smaller, respectively, than the true values, causing the measured $C-V$ profiles to be higher in $n(x)$ and closer to the surface than the actual carrier depth distributions. This is in agreement with our observation that when a difference is observed between profiles measured by the differential $\mathrm{C}-\mathrm{V}$ technique and by the SIMS technique, the $\mathrm{C}-\mathrm{V}$ profile is slightly nearer the surface and sometimes slightly higher. Amron [2] also points out that in the use of the experimental $\Delta C / \Delta V$ to approximate $\mathrm{dC} / \mathrm{dV}$ in the profiling equations, $\Delta \mathrm{C} / \Delta \mathrm{V}<\mathrm{dC} / \mathrm{dV}$ for all values of $\Delta \mathrm{C} / \mathrm{C}$ and the approximation error becomes larger as $\Delta C / C$ increases ( $\varepsilon$ in Amron's notation). Therefore, the computed values of $n(x)$ are greater than the true values of $n(x)$.

\subsection{The Procedure}

The steps in this ion-implanted electrical dopant profile measurement technology in silicon (differential $\mathrm{C}-\mathrm{V}$ profiling using reverse-biased Schottky diodes) are:

- Design experiment: ions, energies, fluences, silicon orientations, angles, and implantation and annealing temperatures;

- Select, identify, and prepare material; 
- Implant contacts;

- Perform experimental implants;

- Anneal implants;

- Anneal contacts (sinter, if evaporated);

- Deposit Schottky diode metallizations;

- Measure Schottky diode areas;

- Measure I-V characteristics, zero-bias capacitance values, and check breakdown voltages;

- Evaluate and select Schottky diodes for profiling;

- Measure differential C-V profiles;

- Analyze, reduce, and compare data;

- Perform Kennedy-O'Brien correction;

- Subtract background substrate dopant density;

- Check reproducibility; and

- Check for time stability.

\subsection{Profiler Circuit Analysis}

The capacitance meter in differential $C-V$ profiling circuitry measures the parallel equivalent circuit shown in figure 2. The analysis that follows assumes that the phase angle of the measuring circuit in the capacitance meter for the diodes is small enough that any resulting error is negligible. That is, it is assumed that $\phi \mathrm{G}_{e q} / \omega$ is negligible compared with the value of capacitance $\mathrm{C}_{\mathrm{eq}}$. This subject is discussed by Anderson, Baron, and Crowell [30]. The phase rejection error of the $C-V$ profiler used in our work is quoted as 1 percent at $Q_{S}=3$; we measured an error of $\sim 1$ percent at $Q_{S}=1$ so the instrument specification is conservative and the phase error is negligible, as assumed above. The circuit actually "seen" by the capacitance meter is shown in figure 3. The shunt resistance $R_{S h}$ is so large $\left(>10^{7} \Omega\right)$ for good diodes in the reverse-biased region where the data are recorded that its influence on the circuit is negligible; $R_{S h}$ can be reduced to $10^{5}$ to $10^{6} \Omega$ without affecting the measured profiles.

The admittance, Yeq, seen by the capacitance meter is:

$$
Y_{e q}=\left[R_{s}+\left(j \omega C_{s}\right)^{-1}\right]^{-1}=\left[R_{s}-\frac{j}{\omega C_{s}}\right]^{-1}=\frac{R_{s}+\frac{j}{\omega C_{s}}}{R_{s}^{2}+\left(\frac{1}{\omega C_{s}}\right)^{2}} \text {. }
$$

In the parallel representation (fig. 2) we obtain:

$$
Y_{e q}=G_{e q}+j \omega C_{e q}=\frac{1}{R_{s}} \frac{\left[1+\frac{j}{\omega C_{s} R_{s}}\right]}{\left[1+\left(\frac{1}{\omega C_{s} R_{s}}\right)^{2}\right]}=\frac{1}{R_{s}} \frac{\left[1+j Q_{s}\right]}{\left[1+Q^{2}\right]} \text {, }
$$

giving 


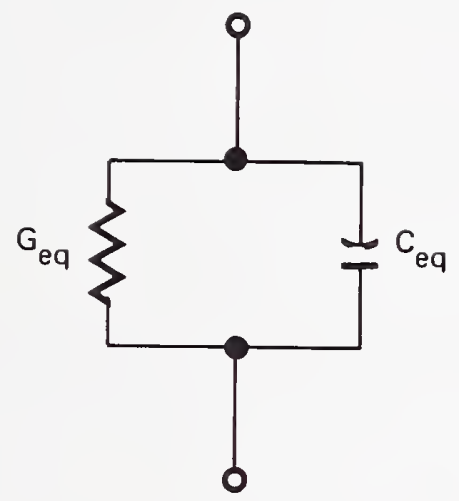

Figure 2. Parallel equivalent circuit.

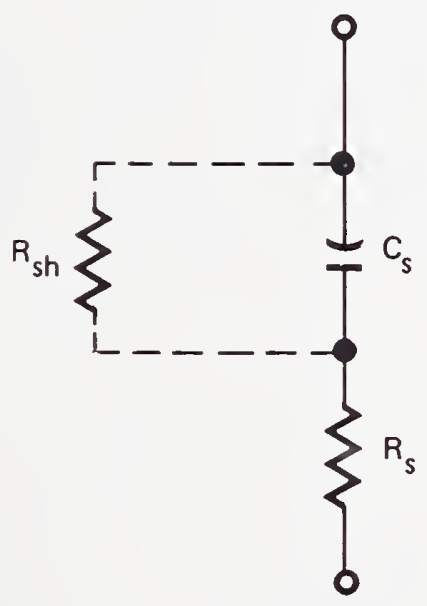

Figure 3. Series equivalent circuit seen by capacitance meter. 


$$
\omega C_{\text {eq }}=\frac{Q_{S}}{R_{S}\left[1+q_{S}^{2}\right]} .
$$

Therefore, the capacitance used for differential $C-V$ profiling leqs (2a) and $(2 \mathrm{~b})]$ is

$$
C_{\text {eq }}=\frac{C_{s}}{\left[1+Q_{s}^{-2}\right]}=\frac{C_{s}}{\left[1+\left(\omega C_{s} R_{s}\right)^{2}\right]} \text {. }
$$

For the $0.12-m m$ diameter diodes used in this study, $R_{S}$ is estimated to be about $2 \mathrm{k} \Omega$ so that at a frequency of $1 \mathrm{MHz}, \mathrm{Q}_{S} \approx 80 / \mathrm{C}_{\mathrm{S}}$, where $\mathrm{C}_{\mathrm{S}}$ is in units of picofarads.

Differentiation of eq (11) yields:

$$
\frac{d C_{e q}}{d V}=\frac{d C_{s}}{d V} \frac{\left[1-\left(\omega C_{s} R_{s}\right)^{2}\right]}{\left[1+\left(\omega C_{s} R_{s}\right)^{2}\right]^{2}} .
$$

Then by substituting eqs (12) and (11) into eq (6a), we obtain:

$$
n(x)_{\text {meas }}=n(x) \text { eq }=\frac{-C_{s}^{3}}{q \varepsilon A^{2} \frac{d C_{s}}{d V}\left[1-\left(\omega C_{s} R_{s}\right)^{4}\right]}=\frac{1}{1-Q_{s}^{-4}} n(x) \text { true }
$$

For $\left(\omega C_{S} R_{S}\right)^{4}<<1$, we can expand the denominator to obtain:

$$
n(x)_{\text {meas }} \doteq\left[1+Q_{s}^{-4}\right] n(x) \text { true }
$$

Thus, the dopant density measured by the profiler, $n(x)$ meas' is an accurate representation of the true density to within about 1 percent if the $Q_{S}$ of the circuit is as low as 3.

Now let us treat the $x$ measured by the profiler in a like manner. Substituting eq (11) into eq (6b) gives:

$$
\mathrm{x}_{\text {meas }} \doteq \frac{\varepsilon A}{C_{S}}\left[1+\left(\omega C_{S} R_{S}\right)^{2}\right]=\left[1+Q_{s}^{-2}\right] x_{\text {true }}
$$

In this case, \& must be $\geqslant 10$ for the error to be 1 percent or less. This is a more stringent requirement than the one derived for $n(x)$.

\subsubsection{Frequency}

The $Q_{S}$ criterion is more easily met by using a low measurement frequency. However, a high frequency is required to guarantee that deep levels do not influence the capacitance measurements and thereby distort the $\mathrm{C}-\mathrm{V}$ profiles from the desired shallow carrier distribution as discussed in section 2.1 
(see also [20] and [21]). A value of $\mathrm{f}=1 \mathrm{MHz}$ is sufficient to overcome this limitation and is typically used in differential $C-V$ profilers, as it is in the experiments and analyses described in this report. Any higher value of frequency hurts the tradeoff criterion for $Q_{S}$.

\subsubsection{Influence of Diode Size}

If the diode diameter $D$ is increased, $C_{\mathbf{S}}$ increases as $D^{2}$ and $R_{\mathbf{S}}$ decreases approximately as $\mathrm{D}^{-1}$, so:

$$
Q_{S} \propto D^{-1}
$$

Therefore, if $\mathrm{D}$ is doubled or quadrupled, $2_{5}$ is halved or quartered and the validity of $\mathrm{n}(\mathrm{x})$ and $\mathrm{x}$ measured by the profiler deteriorates. Increasing the diode area also increases the probability of overlaying a defect in the substrate which can result in an unusable diode. This can be detected from current-voltage measurements before profiles are measured. As the size of the dots is reduced, the edge or perimeter effects increase [34].

\subsubsection{Influence of Substrate Resistivity}

Because $R_{S}$ is approximately proportional to the resistivity $\rho_{\mathbf{S}}$ of the diode substrate, $\rho_{S}$ can be advantageously increased by decreasing $\rho_{S}$. Such an increase in $\mathrm{L}_{\mathrm{s}}$ allows larger diode sizes to be used or higher capacitance samples to be studied, such as those with higher implantation fluence or shallower dopant profile, both leading to higher dopant density. However, a low value of $R_{S}$ implies a high value of background substrate dopant level. The $\mathrm{C}-\mathrm{V}$ profiling technique is limited in its ability to measure high carrier densities by avalanche breakdown near the surface of heavily doped surface regions as the diode bias is increased. The maximum value of $\mathrm{n}(\mathrm{x})$ that can be measured by $\mathrm{C}-\mathrm{V}$ profiling is about $10^{18} \mathrm{~cm}^{-3}$ for shallow doped regions (100 to $200 \mathrm{~nm}$ ) and approaches $10^{17} \mathrm{~cm}^{-3}$ for deep profiles ( 1 to $10 \mu \mathrm{m})$.

A low value of $R_{S}$ leaves little room for measurement between the background carrier density and maximum measured $\mathrm{n}(\mathrm{x})$. Thus, a high value of $\mathrm{R}_{\mathrm{s}}$ is desired to give maximum data in $\mathrm{n}(\mathrm{x})$, but then the detrimental effect on $\mathrm{O}_{\mathrm{S}}$ is encountered. The resulting practical range of background substrate dopant level is roughly $10^{14}$ to $10^{15} \mathrm{~cm}^{-3}$ or about 10 to $100 \Omega \cdot \mathrm{cm}$ for the resistivity of the silicon substrate, varying slightly, depending on whether the carriers are electrons or holes. Substrates of 10 and $100 \Omega \cdot \mathrm{cm}$ resistivity were used in this work. For $\sim 100 \Omega \cdot \mathrm{cm}$ substrates the value of $R_{S}$ calculated using spreading resistance is about $2000 \Omega$. For example, the use of $10 \Omega \cdot \mathrm{cm}$ substrates has allowed somewhat lower energy implants to be profiled ( 5 and $10 \mathrm{keV}$ ). Another help in obtaining profiles of lower energy implants is to use higher fluences in order to increase the dopant density beyond the depth that corresponds to the zero bias depletion depth.

If differential $\mathrm{C}-\mathrm{V}$ profiling data are required in semi-insulating substrates (e.q., high resistivity GaAs) or in substrates on insulators (e.g., sos) where $R_{S}$ is very high, it is necessary to fabricate a lateral geometry configuration where contact is made to the side of the Schottky barrier 
diodes. In such cases the value of $R_{S}$ is not uniform because of pinch-off effects at high reverse biasing conditions [35].

\subsubsection{Error Analysis}

Let us examine the limitations of validity imposed by the requirements that:

and

$$
Q_{S} \geqslant 3 \text { for } n(x)
$$

$$
Q_{S} \geqslant 10 \text { for } x
$$

For the 0.12-mm diodes on the implanted surfaces of our samples, the zerobias capacitance, $C_{0}$, varies from 2 to $20 \mathrm{pF} . \mathrm{C}_{0}$ is the maximum value of $\mathrm{C}_{\mathrm{S}} ; \mathrm{C}_{\mathrm{S}}$ decreases to small values for large reverse bias. Thus, $\mathrm{Q}_{\mathrm{S}}$ varies from large values to 4 , which fulfills the criterion (18a) for $\mathrm{n}(\mathrm{x})$. If $C_{0}$ is $30 \mathrm{pF}, Q_{S} \geqslant 3$ and the maximum error in $n(x)$ is expected to be 1 percent. If $C_{0}$ becomes $50 \mathrm{pF}$ as it can for larger dots, $Q_{S} \geqslant 1.67$. Data may be recorded with an error of $<1$ percent for values of reverse bias that keep $\mathrm{C}_{\mathrm{S}}$ below $30 \mathrm{pF}$. As the applied voltage decreases (that is, as the measured profile approaches the surface) and $\mathrm{C}_{\mathrm{S}}$ exceeds the limiting value of $\mathrm{C}$, the value of $\mathrm{n}(\mathrm{x})$ becomes incorrectly large rapidly, as is illustrated in figure 4 .

The situation for increasing $D$ is more serious for $x$ than for $n(x)$. Examining eqs (16) and (15), we see that if $\mathrm{D}$ is doubled or quadrupled (from 0.12 to 0.25 or $0.50 \mathrm{~mm}$ ), then $\mathrm{a} \mathrm{C}_{0}$ of $10 \mathrm{pF}$ becomes 40 or $160 \mathrm{pF}$, and an $\mathrm{R}_{\mathrm{S}}$ of $2000 \Omega$ becomes 1000 or $500 \Omega$, and $\mathrm{x}_{\text {meas }}=104$ percent or 116 percent of $x_{\text {true }}$. We have measured displacements of these magnitudes for diodes $0.50 \mathrm{~mm}$ in diameter, compared directly with $0.13-\mathrm{mm}$ diodes, as illustrated in figure 5 .

For a $0.12-m m$ diameter diode with $R_{S}=2000 \Omega$, the upper limit on $C_{S}$ for $\leqslant 1$-percent error in $x$ is $8 \mathrm{pF} . A C_{S}$ of $16 \mathrm{pF}$ results in an $x$ that is 4 percent too large. $A C_{S}$ of $20 \mathrm{pF}$ leads to a 6-percent error. Thus we see that either only diodes with $C$ less than $8 \mathrm{pF}$ should be used or the error in the measured $x$ of the $C-V$ profiles should be quoted, or the values of $x$ should be corrected for it.

Voltage breakdown is another characteristic of a diode that can affect a $\mathrm{C}-\mathrm{V}$ profile. For a depth distribution that requires a large applied voltage to deplete it completely, the applied voltage may exceed the breakdown voltage of the diode. This voltage may be 50 to $100 \mathrm{~V}$. Such a situation is illustrated in figure 6. In this figure, the value of $n(x)$ is seen to increase rapidly at diode breakdown. It is also possible for the value of $\mathrm{n}(\mathrm{x})$ to decrease at the breakdown condition.

\subsubsection{Phase Error}

Any nonnegligible phasing error that may exist in the capacitance measuring circuit should be taken into account in the total error analysis. The phase error can be determined for the measuring system by artificially introducing a resistance along with a standard calibration capacitor. The profiler used in this work could be adjusted to minimize any phase angle error. 


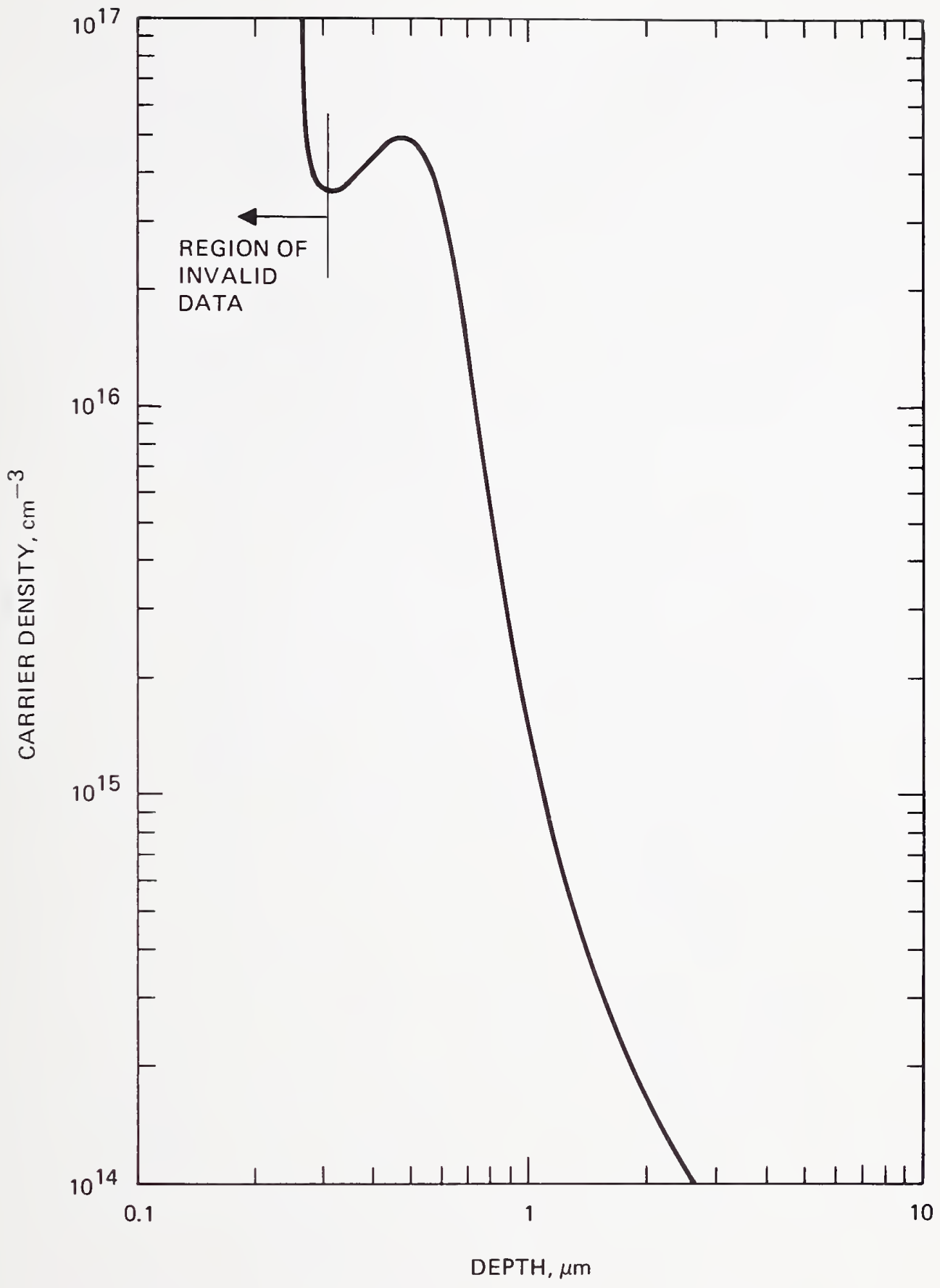

Figure 4. A C-V profile that shows the nature of an error caused by a high sample capacitance. 


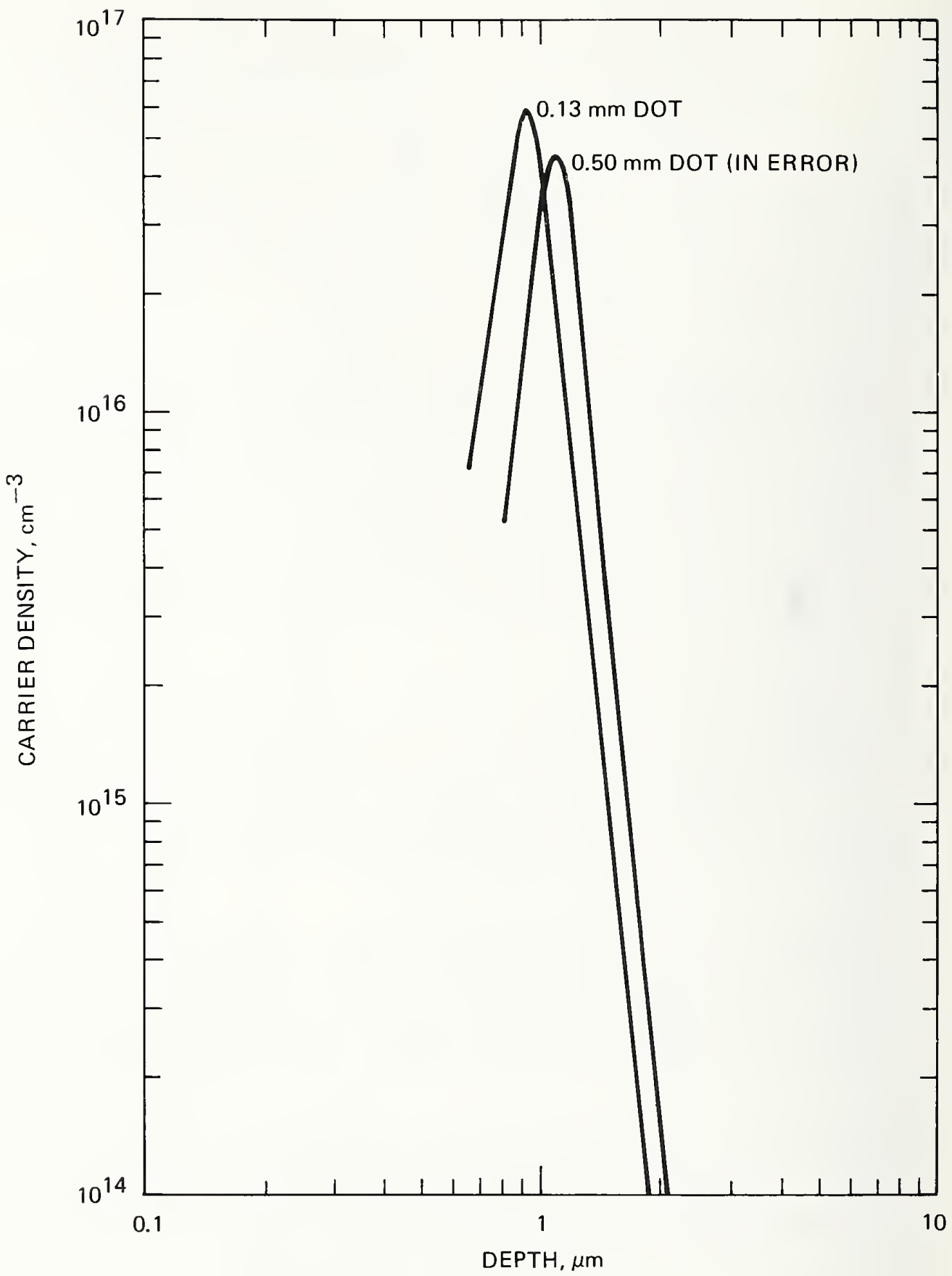

Figure 5. Two $\mathrm{C}-\mathrm{V}$ profiles that show the nature of an error caused by using a sample area that is too large. 


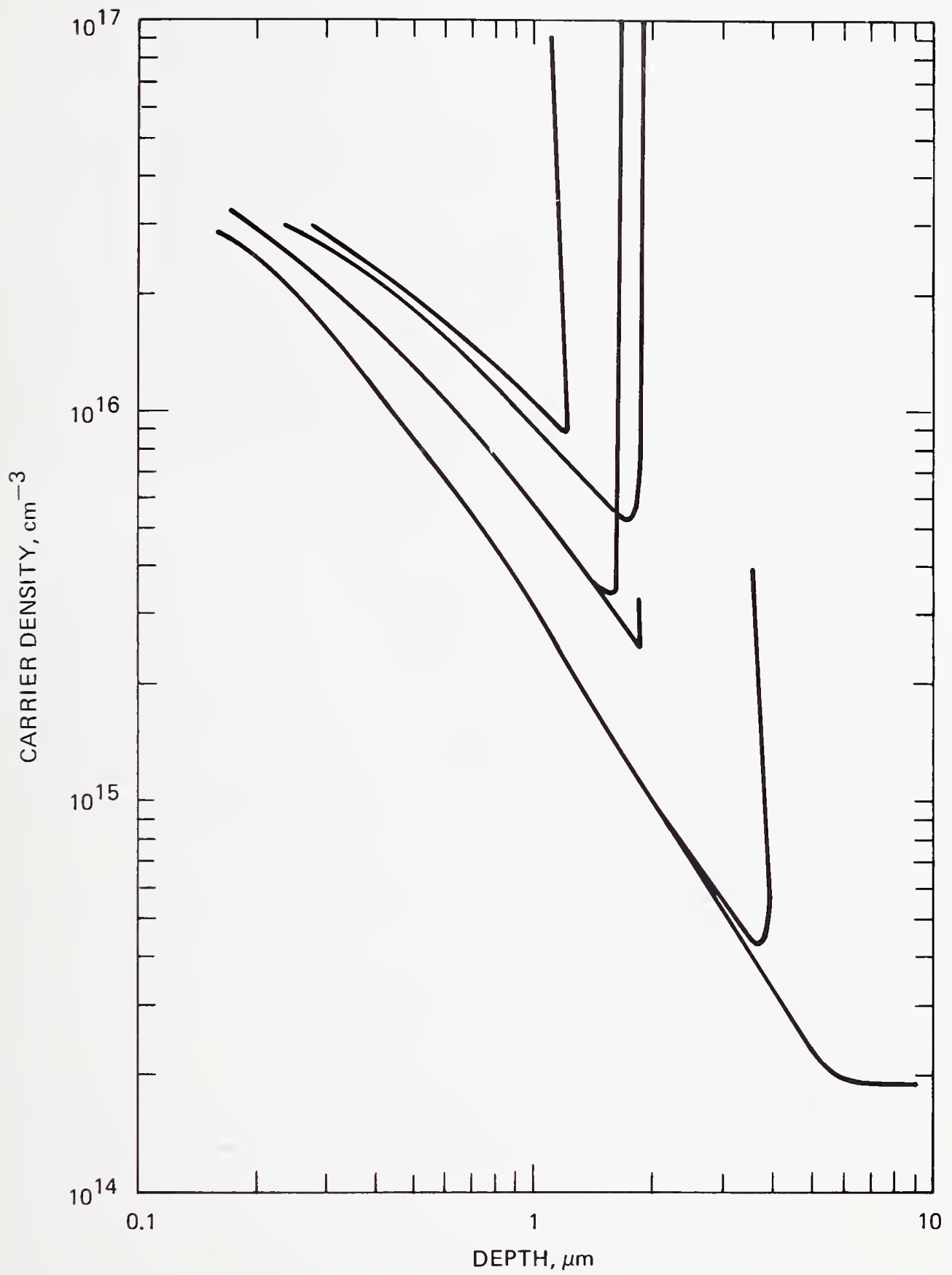

Figure 6. Several $\mathrm{C}-\mathrm{V}$ profiles that show the nature of the loss of data caused by voltage breakdown. 


\subsubsection{Voltage Sweep Rate}

In measuring dopant densities by automatic $\mathrm{C}-\mathrm{V}$ profiling techniques, the reverse bias may be automatically swept for the calculation of density versus depth. The influence of the rate at which the voltage is swept was determined. A profile for $300-k e V$ boron in silicon was repeatedly measured as the voltage sweep rate was varied on an automatic $C-V$ profiler. The results are shown in figure 7 , where five bias voltage sweep rates are plotted on the same figure with the corresponding $C-V$ profiles. The voltage was always started at $20 \mathrm{~V}$ and decreased to $0 \mathrm{~V}$. The two sweep rates above the slowest ( 2 and 3 ) show small distortions in the "tail" region of the distribution. The high rates (4 and 5) show large distortions of the profile indicating erroneously large depths. The highest rate (5) also distorts the curve at the peak of the profile (making the density too low) and on the shallow side of the peak of the implanted distribution (too shallow).

\subsubsection{Ambient Light Intensity}

The intensity of light in the environment of the Schottky barriers during the $\mathrm{C}-\mathrm{V}$ measurements has been observed to influence the shape of the profiles. Light-stimulated carrier generation around the periphery of the Schottky barriers may be the cause. The effect is documented below. C-V profiles were measured for various Schottky barriers on (111) silicon surfaces implanted with $300-\mathrm{keV}$ boron while various levels of light were incident on the barriers. The Schottky barriers were aluminum, titanium-gold, and molybdenum-gold. Light intensities used were: a) room darkened; b) overhead room lights on (normal lighting); and c) a microscope lamp directly illuminating the barriers, such as occurs while contacting the schottky barriers with the gold probe.

The results are shown in figure 8 for each of the three light intensities on each of the three Schottky structures. Observations from these results are:

- The presence of normal room light does not affect the C-V profiles for any of the Schottky structures examined.

- The presence of more concentrated light from a microscope lamp distorts the $\mathrm{C}-\mathrm{V}$ profiles significantly for all three Schottky structures, but in different ways.

- For the aluminum Schottky, the effect of light is to depress the peak artificially and to widen the profile at high densities.

- For both the titanium-gold and molybdenum-gold Schottkys, the effect of light is to increase the height and narrow the width of the peak of the distribution (but more significantly for molybdenum-gold than for titanium-gold), and to move the entire distribution to shallower depth.

- For all three Schottkys, the background dopant density is artificially raised. The trend becomes more pronounced from aluminum to titanium-gold to molybdenum-gold. 


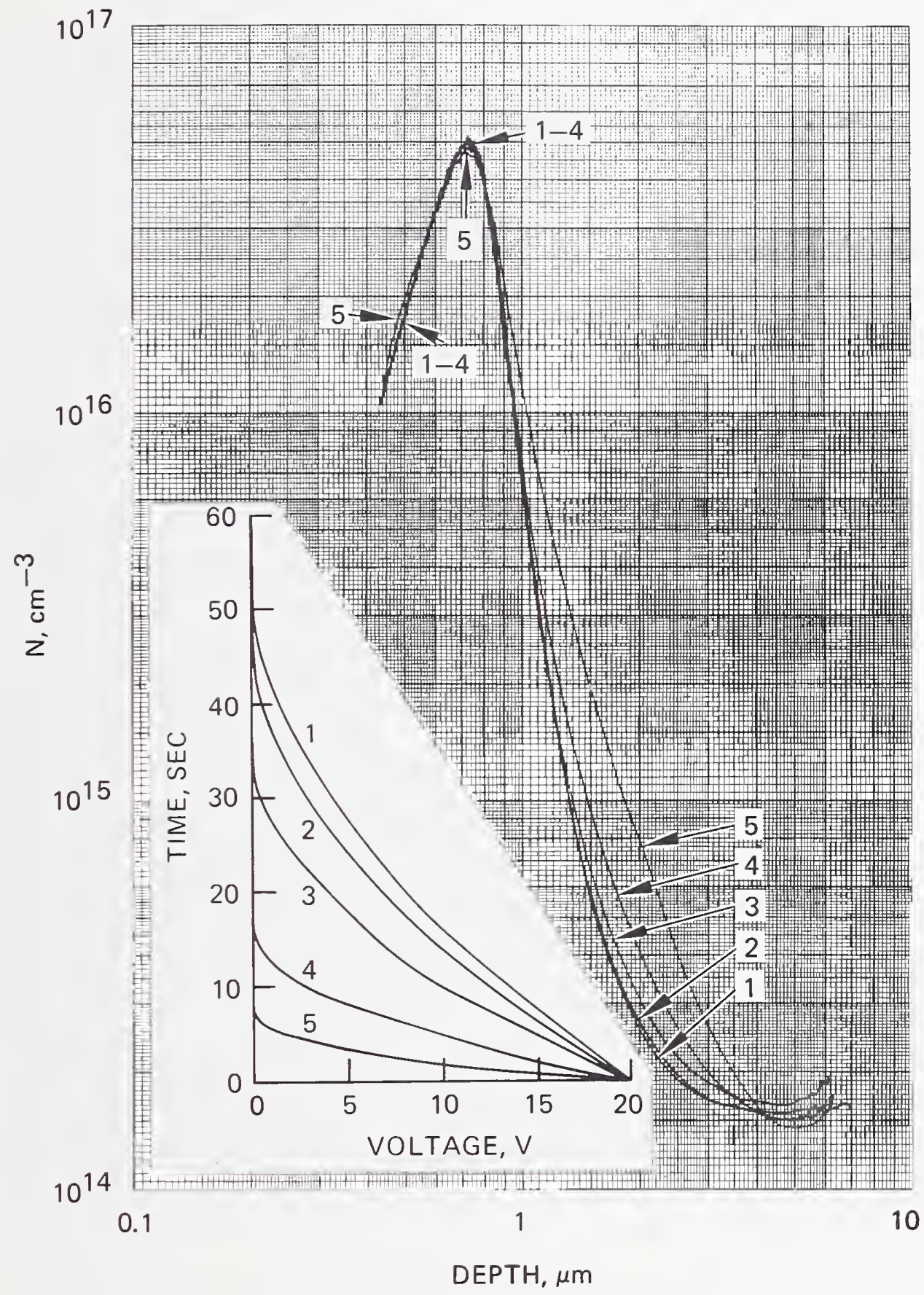

Figure 7. C--V profiles for a silicon specimen implanted with 300-meV boron for various voltage sweep rates shown in the inset. 


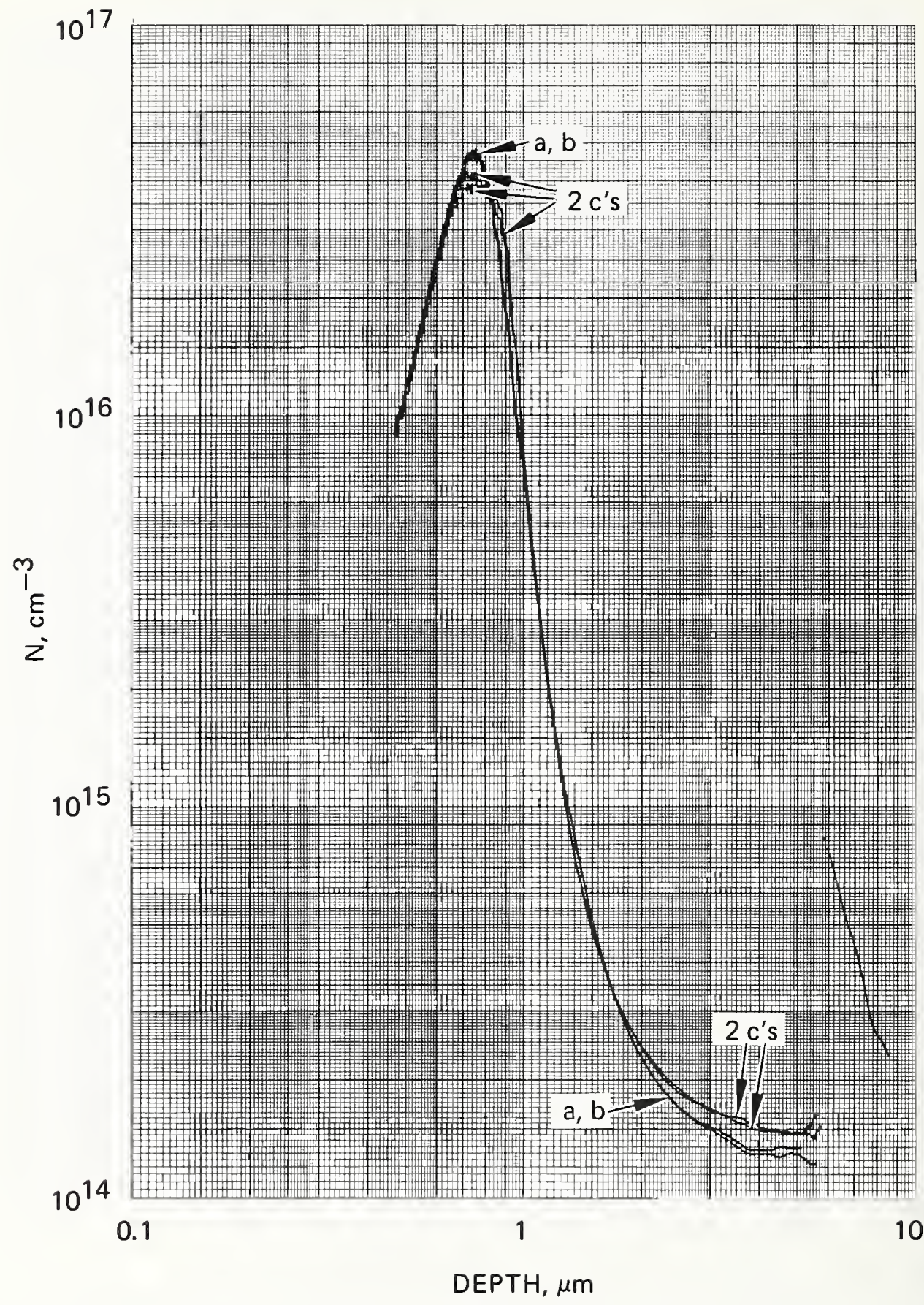

Figure 8a. C-V profiles for varying light intensity environments; aluminum Schottky barrier (300-keV boron in silicon). a) darkened room; b) normal lighting; c) microscope lamp. 


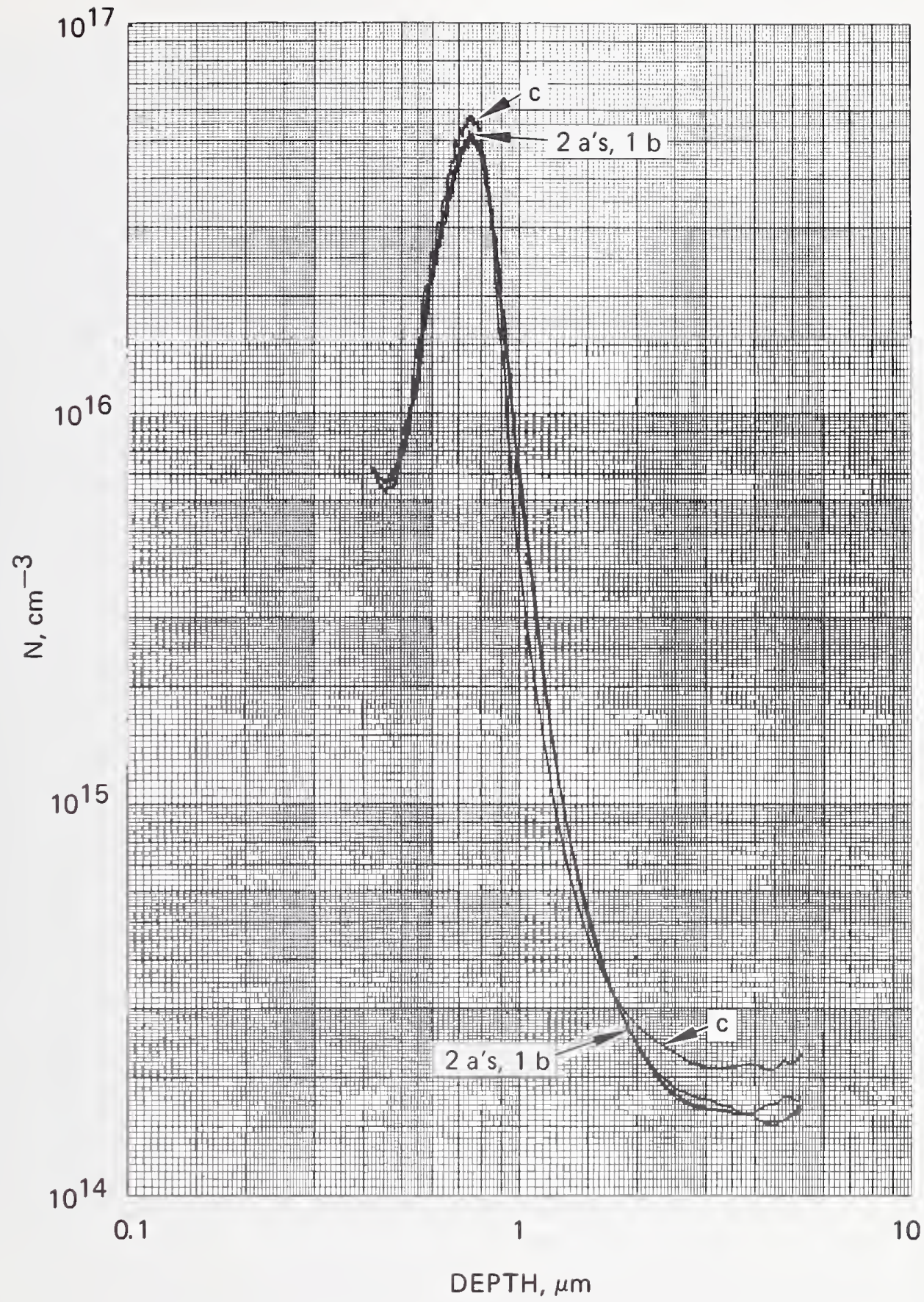

Figure 8b. C-V profiles for varying light intensity environments; titaniumgold Schottky barrier (300-keV boron in silicon). a) darkened room; b) normal lighting; c) microscope lamp. 


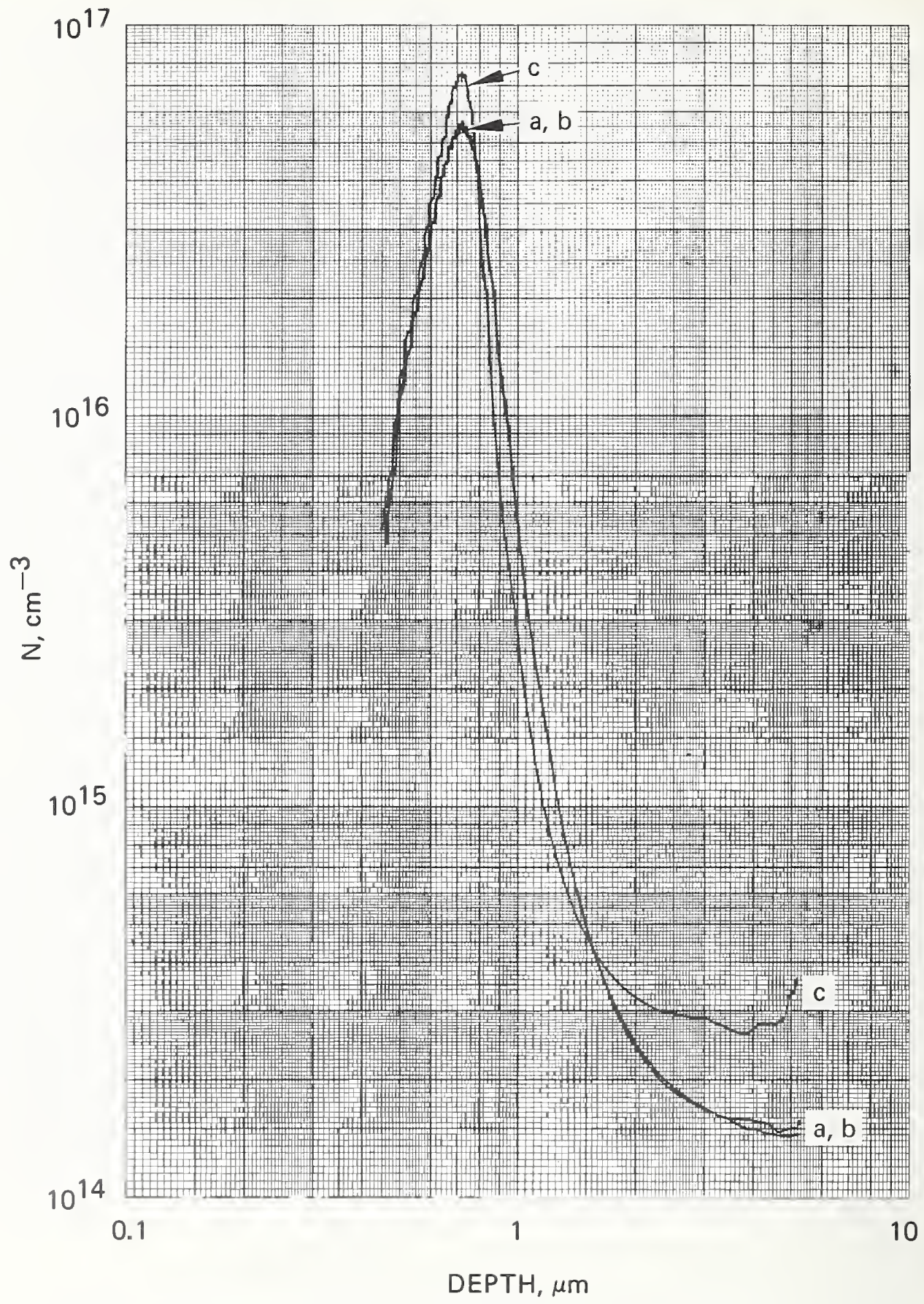

Figure 8c. C-V profiles for varying light intensity environments; molybdenum-gold Schottky barrier (300-keV boron in silicon). a) darkened room; b) normal lighting; c) microscope lamp. 


\subsubsection{Cable Compensation and Zero Calibration}

Two practical details of $\mathrm{C}-\mathrm{V}$ measurements using a capacitance meter involve proper compensation for the probe cable and zeroing of the capacitance meter. Detailed studies of the effect of these two adjustments and how they were performed showed that significantly incorrect profiles can result if these two procedures are not carried out in the manner described below which yields consistent and accurate profiles.

With the probe cable attached for a $\mathrm{C}-\mathrm{V}$ measurement, but not contacting a sample (withdrawn one probe diameter from contact), the cable compensation is adjusted to maximize the capacitance reading on the most sensitive scale and then the capacitance meter is zeroed on the scale on which the measurements will be made (determined by the sample capacitance under zero applied voltage). The capacitance meter should be zeroed each time a different capacitance scale is used. The measured capacitance associated with a probeto-sample spacing of one probe diameter is $\sim 0.01 \mathrm{pF}$, indicating no likely error from this source if cable compensation is carried out.

\subsubsection{Experimental Errors}

The following error analysis is based on the fundamental expressions of eq (6). The error limit on the diameter of the schottky barriers measured optically with a calibrated eyepiece reticle is about 1 percent, so the error limit on the area (A) is about 2 percent. The error in the measurement of capacitance (C) is about 2 percent so the error in $C^{3}$ is 6 percent. The error in $\mathrm{dC} / \mathrm{dV}$ is about 3 percent. Combining these, the rms error in $\mathrm{n}(\mathrm{x})$ is $\sim 7$ percent; and the rms error in $\mathrm{x}$ is $\sim 3$ percent. These error limits are valid only if the measurement frequency, diode resistance, and diode capacitance are such as to make the diode $Q$ be greater than 5 , as shown above.

During $\triangle-V$ profiling for cases where the zero-bias capacitance is large enough to cause some error, but no error occurs at higher biases, the deep portion of the depth distribution (higher reverse bias) is accurate; but closer to the surface where the value of $C$ surpasses the value of negligible error, $n(x)$ becomes erroneously high, the error becoming larger as the surface is approached. For cases of deep profiles where larqe reverse bias is required to deplete through the charge distribution, diode leakage currents and finally breakdown may occur, causing errors in the profiles. Current-voltage measurements of the diodes prior to profiling can be used to determine if such effects will occur for the required reverse biases. We have found that carefully prepared Schottky barrier diodes on $p$ - and $n$-type silicon surfaces implanted with $\sim 10^{12} \mathrm{~cm}^{-2}$ ion fluences will support reverse bias in excess of $100 \mathrm{~V}$ and that such values of bias are required to deplete through deep channeled profiles ( 5 to $10 \mu \mathrm{m})$.

\subsection{Summary}

In summary, this analysis shows that it is essential to use diodes with a $\mathrm{C}_{0}$ less than the limits established in the above analysis or to record data only for capacitances below these limits if the as-measured depth distributions of electrical activity are to be valid within 1 percent. 
Otherwise, the profiles should be corrected according to this treatment, or appropriate errors should be quoted.

The zero-bias capacitance $\mathrm{C}_{0}$ of a diode can be controlled via dot size and dopant density. Higher dopant densities can be studied by decreasing the dot size. Profiles can be obtained closer to the surface by decreasing the dot size or the substrate resistivity, with a corresponding loss of profile at lower densities in the latter case.

Profile measurements should be made only for diodes that exhibit good I-V characteristics in both forward and reverse bias. The diodes should not break down or leak significantly for voltages up to those reguired to deplete through the implanted region, that is, until the complete profile is obtained, or data should be reported only for voltages up to the breakdown or leakage values.

Our experience has shown that by using the criteria defined above, reproducible and consistent implanted profiles can be obtained for diodes that exhibit 0.5- to 30-pF capacitance and depth distributions from $80 \mathrm{~nm}$ to $10 \mu \mathrm{m}$. For distributions deeper than $\sim 3 \mu \mathrm{m}$, applied reverse bias up to $100 \mathrm{~V}$ may be required to obtain a complete profile from one sample. Dopant densities can be measured from $10^{14} \mathrm{~cm}^{-3}$ up to about $3 \times 10^{17} \mathrm{~cm}^{-3}$ at depths below $0.3 \mu \mathrm{m}$, and up to about $8 \times 10^{16} \mathrm{~cm}^{-3}$ at about $1 \mu \mathrm{m}$, with a gradation between. The maximum implantation fluence that can be profiled is about $2 \times$ $10^{12} \mathrm{~cm}^{-2}$ for distributions that extend $\geqslant 1 \mu \mathrm{m}$ in depth, and about $2 \times 10^{13}$ $\mathrm{cm}^{-2}$ for depths of about 0.1 to $0.2 \mu \mathrm{m}$, with a gradation between.

It is important to determine for a given $\mathrm{C}-\mathrm{V}$ profiler what maximum voltage sweep rate does not distort the depth distribution and then to keep the sweep rate below this value. The maximum sweep rate for the $C-V$ profiler used in this work is $\sim 0.5 \mathrm{~V} / \mathrm{s}$. Care must also be taken to ensure that profile distortions are not caused by intense light shining on the diode that is under reverse bias. Normal room light was found in this work to cause no distortions, but localized intense light did cause a significant change.

\section{SCHOTTKY BARRIERS}

\subsection{Introduction}

The physics and practical aspects of the use of schottky barriers on semiconductor surfaces is a well-established and studied field $[36-56,20$, 24]. Their use for measuring the properties of ion-implanted layers has been studied specifically $[48-50,52,20]$. Our need in this study was for stable, reproducible schottky diodes with hard current-voltage (I-V) characteristics and high breakdown voltage $\left(V_{B}\right)$. The literature indicated that gold and aluminum were possibilities and that certain difficulties might be encountered, such as aging (time-dependent effects). Therefore, we studied several metallization systems on both $p$-type and $n$-type implanted silicon to verify what systems were valid for this project. The metals chosen were gold on n-type and aluminum on p-type silicon. 


\subsection{Metals for Schottky-Barrier Formation on $p$-Type and n-Type Silicon}

We have studied and compared the four metallizations: aluminum, gold, titanium-gold, and molybdenum-gold, on p-type (boron-implanted) and on n-type (phosphorus- or arsenic-implanted) (111) silicon surfaces. We studied cleaned (unetched) surfaces and surfaces etched in concentrated hydrofluoric acid (HF) just prior to Schottky barrier deposition. We followed the aging of these Schottky barrier metallizations until stabilization was reached. The I-V characteristics of the barriers and the dopant profiles obtained by $\mathrm{C}-\mathrm{V}$ measurements of the underlying implanted surface were recorded. The results are reported below.

A set of eight $100 \Omega \cdot \mathrm{cm}, p$-type samples was implanted with $300-\mathrm{keV}$ boron, four with HF-etched surfaces and four with unetched surfaces, and their $\mathrm{C}-\mathrm{V}$ profiles were followed for about 18 months. The four metal systems were evaporated in an electron-beam evaporator at approximately $10^{-7}$ Torr. The Schottky barriers were dots $0.13,0.25,0.50$, and $1.0 \mathrm{~mm}$ in diameter, defined by a contacting mask, in the metal film which was $100.5( \pm 2.0) \mathrm{nm}$ thick.

Four of the surfaces were cleaned by ultrasonic degreasing followed by acetone, alcohol, and deionized water rinses. Four other surfaces were dipped in a standard $\mathrm{HF}$ etch for $15 \mathrm{~s}$ and rinsed. The metallizations were evaporated sequentially on these latter four samples. All Schottky barriers for all four metal systems on the etched surfaces were shorted initially and remained shorted. No C-V profiles were ever obtained for any of them. Some indication of an increase in shorted resistance was observed with time. These results are consistent with the work of Turner and Rhoderick [45].

Good Schottky I-V characteristics and fair C-V profiles were obtained immediately for the four metal systems placed on cleaned, but unetched, silicon surfaces (assumed to have $\leqslant 3 \mathrm{~nm}$ of native oxide present at the time of deposition). For the p-type surfaces, the $\mathrm{C}-\mathrm{V}$ profiles changed slightly during the first two or three hours and then stabilized. Schematic representations of the $\mathrm{C}-\mathrm{V}$ profiles showing the characteristics of the initial and stabilized $\mathrm{C}-\mathrm{V}$ profiles for the four metallization systems are shown in figure 9. In all cases, the measured background dopant level decreased with time until it reached the substrate dopant level. Aluminum was the most stable metallization, changing only slightly in background level; it is felt to be the best choice for routine work on p-type silicon. Gold gave information closer to the surface, but aged significantly, and the measured carrier densities are higher than predicted analytically. Titaniumgold gave the least information and changed the most with time. Molybdenumgold aged some and was the most difficult to deposit. Aluminum is the easiest metal system to use, ages the least, and has given the most reliable data. We have checked some aluminum Schottky barriers after 30 months, and the $\mathrm{C}-\mathrm{V}$ profiles have not changed during that time.

The same four metallization systems were studied for $n$-type (phosphorus) implanted silicon. The I-V, C-V, and capacitance data for the four Schottky barrier systems are shown in figure 10. Gold was good and was therefore always used in this program. Titanium-gold was universally bad. Aluminum and molybdenum-gold were sometimes fair or even good, but often bad. The specific features of the bad $I-V$ and $C-V$ curves are shown in the figure. It 


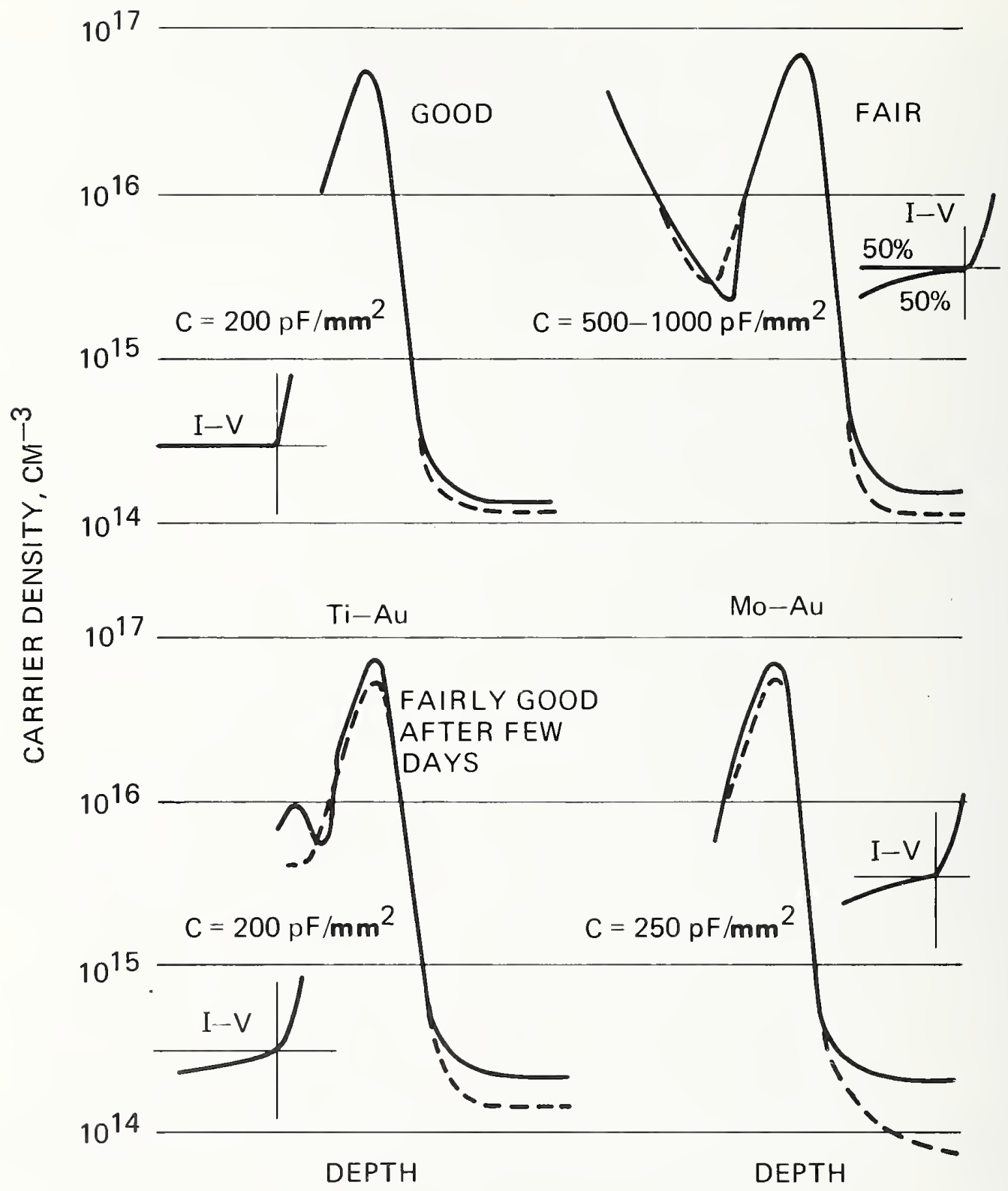

Figure 9. C-V profiles and Schottky barrier data for four metallization systems on p-type, $\sim 100 \Omega \cdot \mathrm{cm}$ implanted silicon surfaces (300-keV boron). (Solid curves: immediately after metal deposition; dashed curves: after stabilization. Both scales are logarithmic. Vertical scale is density ranging from $10^{14}$ to $10^{17} \mathrm{~cm}^{-3}$; horizontal scale is depth ranging from 0.1 to $10 \mu \mathrm{m}$.) 


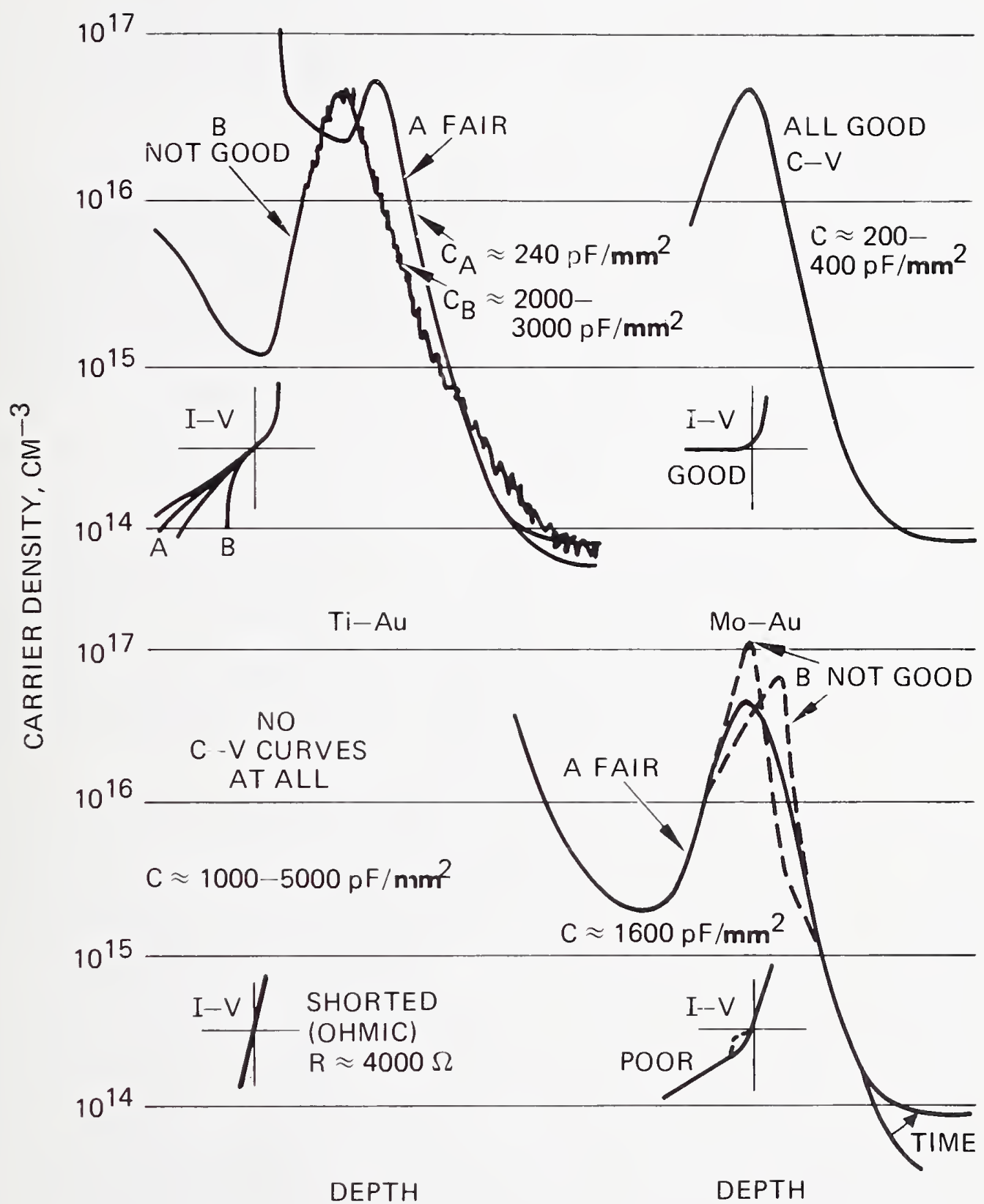

Figure 10. C-V profiles and Schottky barrier data for four metallization systems on $n$-type, $\sim 100 \Omega \cdot \mathrm{cm}$ implanted silicon surfaces $(600-\mathrm{keV}$ phosphorus). (Solid curves: immediately after metal deposition; dashed curves: after stabilization. Both scales are logarithmic. Vertical scale is density ranging from $10^{14}$ to $10^{17} \mathrm{~cm}^{-3}$; horizontal scale is depth ranging from 0.1 to $10 \mu \mathrm{m}$.) 
was learned that the I-V curve quality and the value of $C$ can almost always be used to determine whether a $\mathrm{C}-\mathrm{V}$ curve is going to be good or bad. The value of $\mathrm{C}$ should be 200 to $400 \mathrm{pF} / \mathrm{mm}^{2}$ for the $\sim 0.7-\mu \mathrm{m}$ deep profile shown and the I-V curve should be rectifying. The metal film thickness should be between 50 and $250 \mathrm{~nm}$.

\subsection{Schottky Barrier Height Measurement and Aging}

Three experimental techniques for measuring schottky barrier heights have been the $I-V, C^{-2}-V$, and photoemission threshold techniques reviewed by van Otterloo and Gerritsen [56]. They conclude that, of these, the $c^{-2}-V$ method is capable of producing the most accurate results. In the $\mathrm{C}^{-2}-\mathrm{V}$ technique, the reciprocal of the square of the differential capacitance is plotted versus the applied reverse bias (and slightly into forward bias). The Schottky barrier height $\phi_{\mathrm{B}}$ is determined from the intercept of a straight line drawn through these data as follows:

$$
\phi_{\mathrm{B}}=\text { Intercept }+\frac{\mathrm{kT}}{\mathrm{q}}+\phi_{\mathrm{F}}+\mathrm{I} \cdot \mathrm{F} \cdot,
$$

where $\phi_{F}$ is the Fermi energy relative to $E_{C}$ (the bottom of the conduction band) and I.F. is the image force effect. The terms I.F. and kT/q are generally considered negligible $(\sim 0.02 \mathrm{eV})$. Examples of $\mathrm{C}^{-2}-\mathrm{V}$ plots for aluminum Schottky barriers on $100 \Omega \cdot \mathrm{cm}$ p-type (100), (110), and (111) silicon (float-zone-refined) and for gold Schottky barriers on $100 \Omega \cdot \mathrm{cm} n$-type (100) and (111) silicon are shown in figures 11 and 12. The intercepts from which values of $\phi_{\mathrm{B}}$ are obtained from eq (18) are indicated. values of $\phi_{\mathrm{B}}$ from $\sim 0.65$ to $0.85 \mathrm{~V}$ are inferred.

As stated by Turner and Rhoderick [45], there is a wealth of evidence in the literature that a silicon surface is inevitably covered with a thin oxide layer of the order of $1 \mathrm{~nm}$ thick. Muret and Deneuville [55] report that chemically prepared silicon surfaces are covered with $0.5 \mathrm{~nm}$ of oxide as measured by ellipsometry. These 0.5 and $1 \mathrm{~nm}$ numbers are consistent with our Rutherford backscattering measurements that indicate that our implanted silicon surfaces are covered with oxygen corresponding to about two monolayers of silicon dioxide. These layers are so thin that electrons can easily tunnel through them, but the effective barrier height can also be affected. Positive ions moving under the influence of the high built-in field to be neutralized at the metal surface migrate less easily through the oxide layer. During this migration, a temporary dipole would modify the barrier height in a time-dependent way. This is the probable mechanism for aging of Schottky barriers that is discussed in the literature. Aging of Schottky barriers is discussed for silicon by Turner and Rhoderick [45] and Muret and Deneuville [55], and by Nicollian et al. [51] for gallium arsenide.

\subsection{Schottky Barrier Area and Quality Measurement Techniques}

Two key factors in the measurement of $\mathrm{C}-\mathrm{V}$ profiles using schottky barriers are the determination of the area and the quality of the Schottky barrier metallization. Area determination is possibly the largest source of error in the measurement of dopant profiles by the $\mathrm{C}-\mathrm{V}$ technique. Schottky 


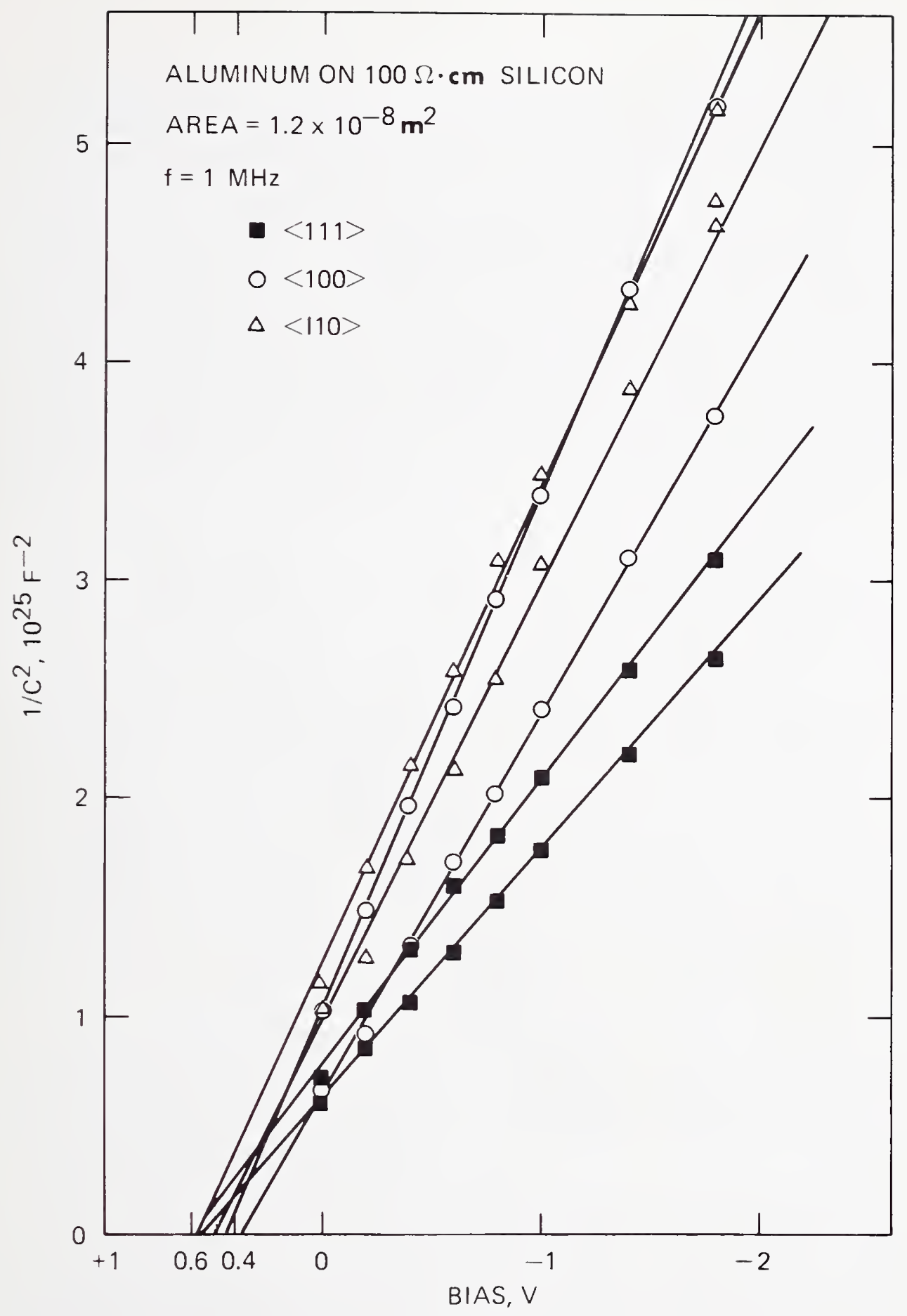

Figure 11. Plots of $\mathrm{C}^{-2}-\mathrm{V}$ Schottky barrier height determination; aluminum on p-type silicon. 


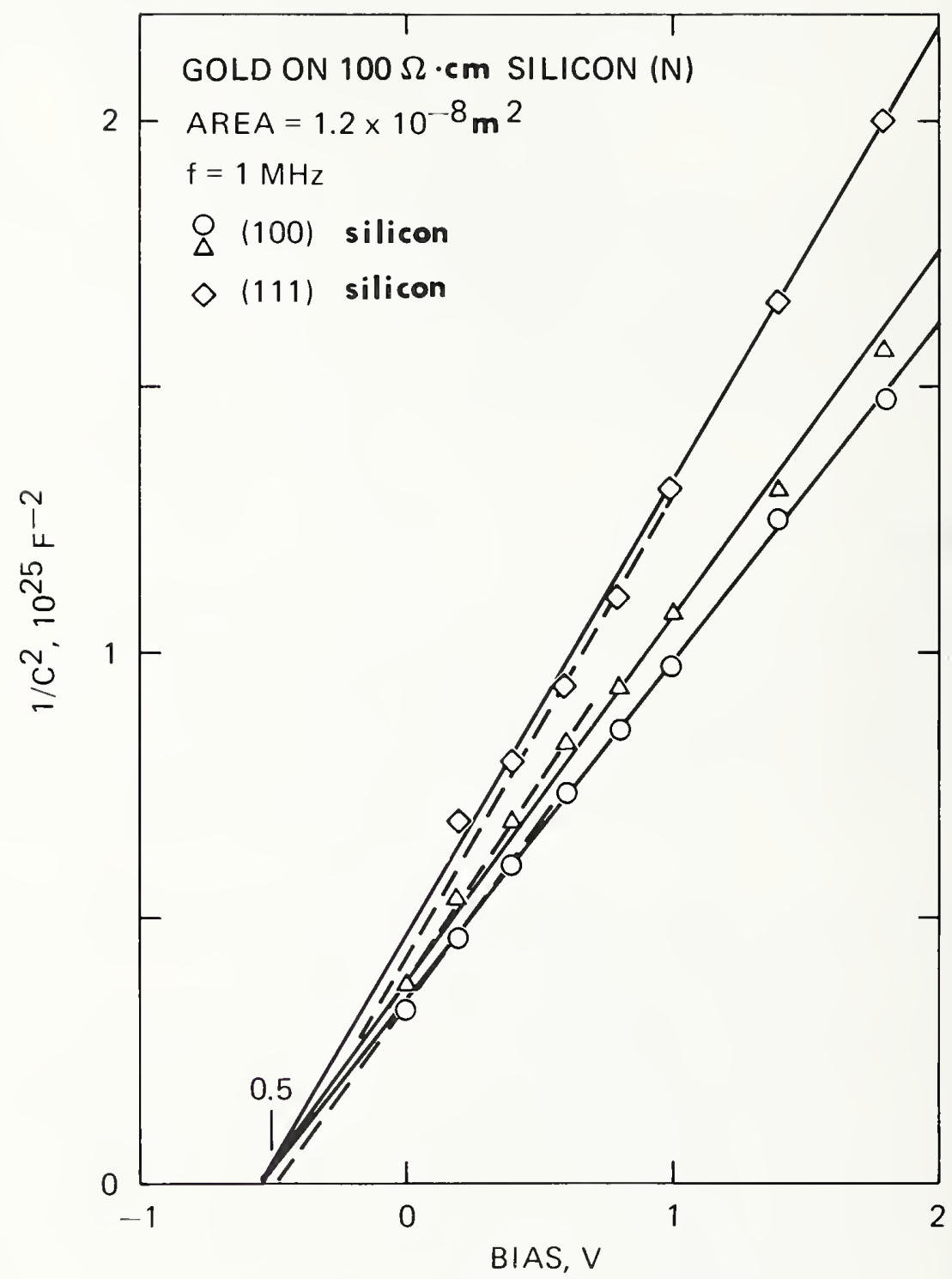

Figure 12. Plots of $\mathrm{C}^{-2}-\mathrm{V}$ Schottky barrier height determination; gold on n-type silicon. 
barriers were fabricated for this work with diameters of $0.13,0.25,0.50$ and $1.0 \mathrm{~mm}$. The I-V characteristics of the $0.13-\mathrm{mm}$ dots were consistently good. Acceptable I-V characteristics and $C-V$ profiles were obtained for some of the $0.25-\mathrm{mm}$ dots.

The areas of the Schottky barrier metallizations used were calculated from the average of two orthogonal measurements of the diameter. The diameter measurements were accurate to about 1 percent. Dots with irregular edges were not used for $\mathrm{C}-\mathrm{V}$ measurements, nor were significantly nonround dots or dots with damage or imbedded dirt used. Optically unobservable errors and flaws can result from spots of poor adhesion or defects in the silicon beneath the surface. We feel that such unobservable errors can be eliminated by measuring $\mathrm{C}-\mathrm{V}$ curves for six or eight Schottky barriers and discarding any curves that deviate significantly from the majority that agree closely. Usually one out of six $0.13-\mathrm{mm}$ dots was in disagreement, while five agreed, indicating a yield of about 83 percent.

The current-voltage characteristics of the schottky barriers were measured on a curve tracer set at $10 \mu \mathrm{A}$ and $2 \mathrm{~V}$. Some typical examples for $0.13-$ and $0.25-\mathrm{mm}$ dots on $n$ - and p-type silicon are shown in figure 13. A description of the samples is shown in table 1. The I-V characteristics of Schottky barriers that gave good $C-V$ profiles are shown in $a, b$, and $c$. I-V characteristics of leaky barriers which nevertheless provided useful $\mathrm{C}-\mathrm{V}$ profiles are shown in $\mathrm{a}^{\prime}$ and $\mathrm{b}^{\prime}$. Schottkys with I-V characteristics like those shown in $a^{\prime \prime}, b^{\prime \prime}, d$, and $d^{\prime}$ produced unreliable or no C-V profiles.

\subsection{Attempts to Improve $\mathrm{C}-\mathrm{V}$ Profiles of Schottky Barriers}

Four experiments were carried out to determine the merits of several silicon surface treatments to improve the $\mathrm{C}-\mathrm{V}$ characteristics of Schottky barriers. One of these, which had negative results, was carried out as part of the ongoing aging study described in the previous sections. Etching the surface in HF to remove the native surface oxide prior to depositing the Schottky metal was found not to provide improved characteristics.

In another experiment a shallow $p^{+}$or $n^{+}$layer was formed at the surface before deposition of the Schottky barrier by implanting low energy boron or phosphorus. A $10-\mathrm{keV}, 5 \times 10^{11} \mathrm{~cm}^{-2}$ boron implant made on the surface of a standard $300-\mathrm{keV}, 1.5 \times 10^{12} \mathrm{~cm}^{-2}$ boron implant annealed at $750^{\circ} \mathrm{C}$ had no effect on the $\mathrm{C}-\mathrm{V}$ measured dopant profile.

Another experiment involved annealing a 300-keV boron-implanted sample in air at $900^{\circ} \mathrm{C}$ instead of in the standard dry argon or nitrogen annealing

environment. This procedure affected the $\mathrm{C}-\mathrm{V}$ profile. The value of $\mathrm{R}_{\mathrm{p}}$ was slightly larger than the norm, but no more so than some of the Schottky barriers that deviated from the norm of normally annealed samples. The value of $\mathrm{N}_{\max }$ was normal and the profile on the deep side of the peak was normal. The capacitance at the peak itself was unstable. The shallow side of the peak of the profile to the surface was destroyed. The curve dropped only slightly from the peak of the distribution, then shot vertically upward between 0.4 and $0.2 \mu \mathrm{m}$, and finally moved deeper as the applied voltage decreased to zero. The surface region to a depth of about $0.5 \mu \mathrm{m}$ did not yield valid $\mathrm{C}-\mathrm{V}$ profile information. 

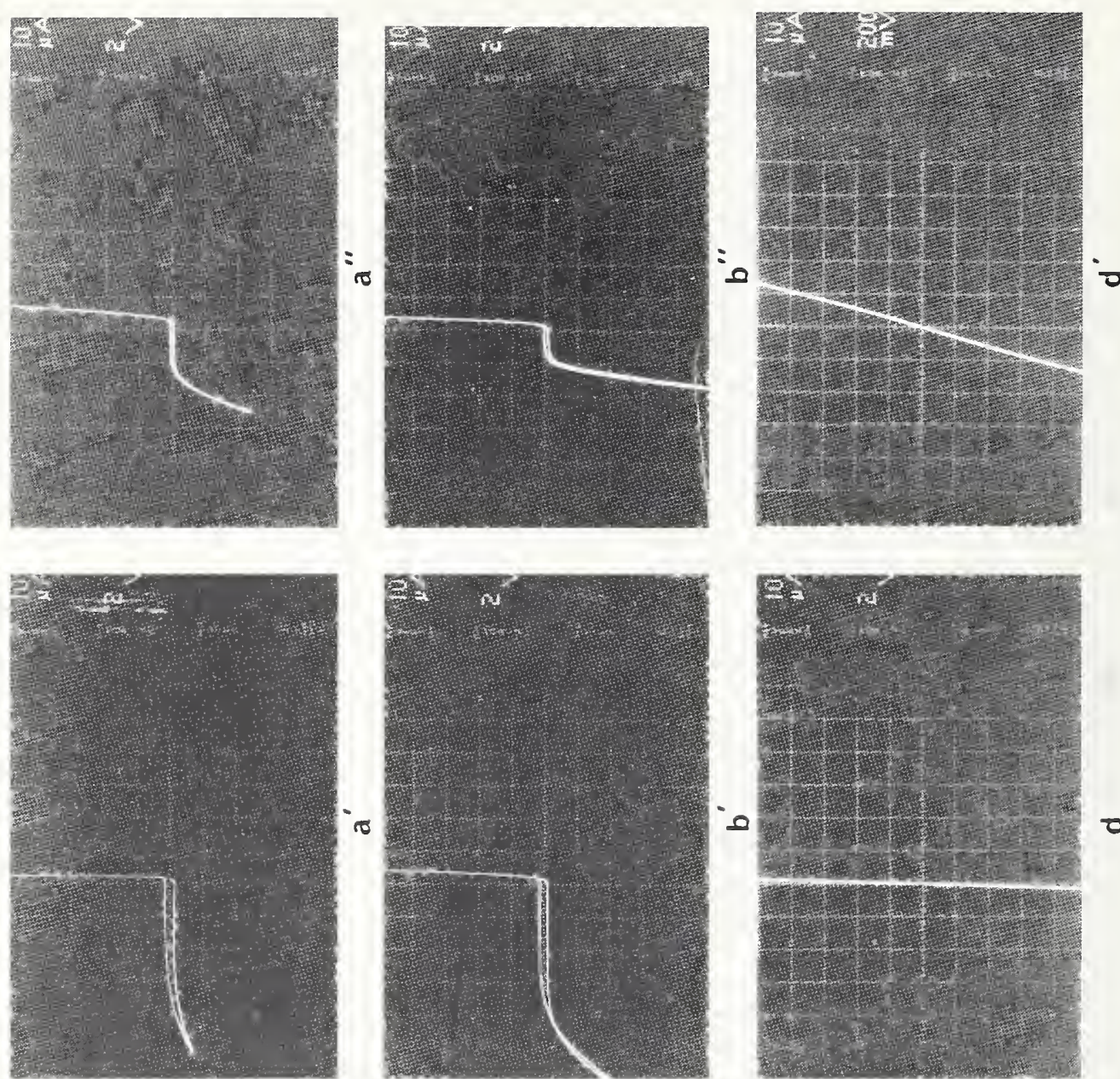

1
0
0
0
01

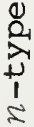

兽

$1 \div$

थ्त प

동 응

$\backsim$ 品

4 U

(1) 4

त्र 0

(⿻)

ऽ 0

$>+$

प्रे

$+4$

0 U

U

$\gamma$

눙 둥

4.

U

स

U

- 40

(1)

I)

U

(1)

\& 0
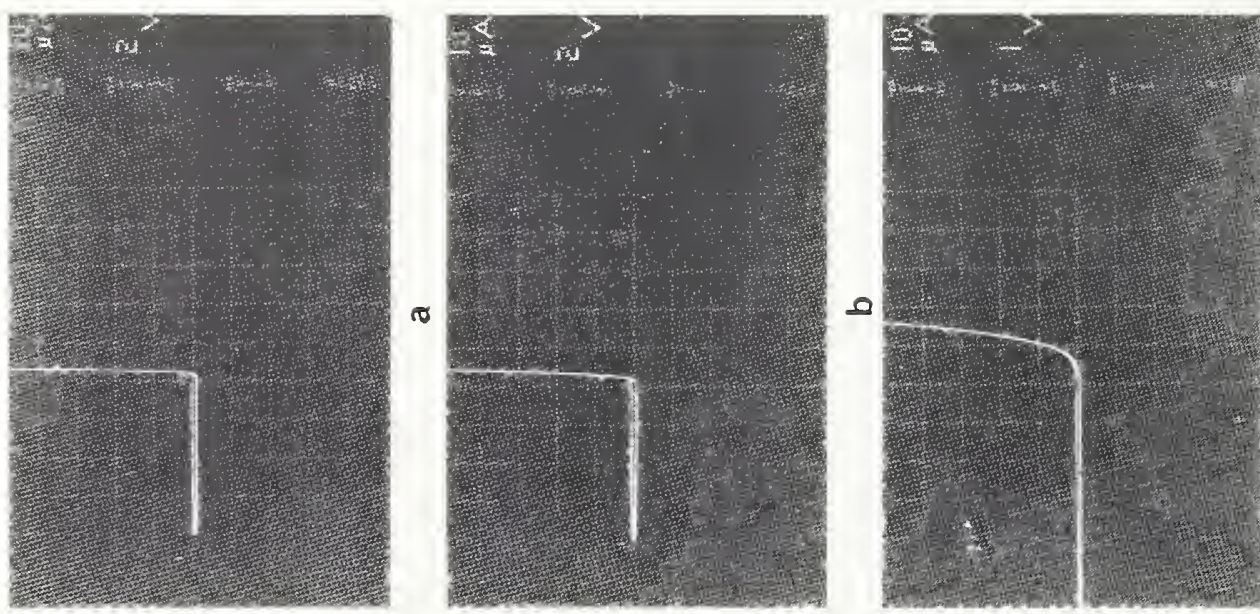

0
$>\quad 0$

$\rightarrow 4$

H

-1 U

U

$-\overrightarrow{0}$

है

u हा.

mं

-

(1) 5

- 10

है 을 ज्ञ 
Table 1. Typical Schottky Barrier Structures on Ion-Implanted Silicon Surfaces.

Identification ${ }^{\mathrm{a}} \quad$ Implant Diameter $(\mathrm{mm})$ Metal $\mathrm{C}_{0}(\mathrm{pF})$

$\begin{array}{llllc}\text { a } & 300-\mathrm{keV} \text { boron } & 0.13 & \text { aluminum } & 2.5 \\ \mathrm{a}^{\prime} & 300-\mathrm{keV} \text { boron } & 0.25 & \text { aluminum } & 11-14 \\ \mathrm{a}^{\prime \prime} & 300-\mathrm{keV} \text { boron } & 0.25 & \text { aluminum } & 11-14 \\ \mathrm{~b}^{\prime} & 600-\mathrm{keV} \text { phosphorus } & 0.13 & \text { gold } & 2.7 \\ \mathrm{~b}^{\prime} & 600-\mathrm{keV} \text { phosphorus } & 0.25 & \text { gold } & 11-14 \\ \mathrm{~b}^{\prime \prime} & 600-\mathrm{keV} \text { phosphorus } & 0.25 & \text { gold } & 11-14 \\ c^{\prime} & 300-\mathrm{keV} \text { boron } & 0.13 & \text { titanium-gold } & 2.6 \\ \mathrm{~d}^{\prime} & 300-\mathrm{keV} \text { boron } & 0.13 & \text { aluminumb } & 15 \\ \mathrm{~d}^{\prime} & 300-\mathrm{keV} \text { boron } & 0.13 & \text { aluminumb } & 15\end{array}$

a I-V characteristics shown in figure 13.

b Silicon dip etched in $\mathrm{HF}$ before aluminum deposition. 
Four samples implanted with 300-keV boron were selected from other experiments which had already been carried through the $\mathrm{C}-\mathrm{V}$ profiling stage and were successively annealed at $100^{\circ} \mathrm{C}, 200^{\circ} \mathrm{C}$, and $250^{\circ} \mathrm{C}$ in air, while $\mathrm{C}-\mathrm{V}$ profiles were measured after each annealing step. One sample, which had been annealed at $750^{\circ} \mathrm{C}$ and yielded a normal $\mathrm{C}-\mathrm{V}$ profile, was chosen as a control sample to see what effect this heat treatment had on a normal sample; the measured range and straggle parameters of this sample did not change, but the shape to the curve became slightly more Gaussian and smoother. The other three samples were chosen because of their originally poor $\mathrm{C}-\mathrm{V}$ profiles to see if thermally accelerated aging could improve their profiles.

One of these samples had been annealed at $450^{\circ} \mathrm{C}$ and should have been normal, but all dots initially produced $\mathrm{C}-\mathrm{V}$ profiles that were too shallow and too high in dopant density, or showed a double peak, one at nearly the correct depth and one closer to the surface. The $100^{\circ} \mathrm{C}$ heat treatment caused no change. The $200^{\circ} \mathrm{C}$ treatment resulted in a great improvement. All dots produced nearly normal curves; some exhibited a rising tail to the surface. After the $250^{\circ} \mathrm{C}$ treatment, some improvement occurred in the deep side tail, but the surface side of the peak became differently sloped and curved too much. This experiment led to the tentative conclusion that a $200^{\circ} \mathrm{C} \pm 25^{\circ} \mathrm{C}$ heat treatment would not harm good $\mathrm{C}-\mathrm{V}$ profiles and might improve initially poor ones.

The remaining two samples were random and aligned implants annealed at $1050^{\circ} \mathrm{C}$. Most of the dots on these two samples had initially produced no profile at all; one or two dots had given a peak at the proper depth, but were unintelligible everywhere except at the peak, yielding only a value of $\mathrm{R}_{\mathrm{p}}$. The $100^{\circ} \mathrm{C}$ and $200^{\circ} \mathrm{C}$ heat treatments had no effect at all. The $250^{\circ} \mathrm{C}$ treatment seemed to have a slight effect on the curves, but produced no improvement. It is known from SIMS measurements [18] that boron begins to diffuse at about $900^{\circ} \mathrm{C}$ and that by $1050^{\circ} \mathrm{C}$ the boron moves significantly, some probably to the surface. The tentative conclusion is that annealing at temperatures above $900^{\circ} \mathrm{C}$ is not satisfactory.

\subsection{Summary}

In the preceding sections, we discussed a number of aspects of Schottky diodes appropriate for differential $\mathrm{C}-\mathrm{V}$ profiling. Some of the conclusions of this work are listed below:

- Schottky diodes must have fairly hard I-V characteristics to give valid $\mathrm{C}-\mathrm{V}$ profiles.

- Schottky diode areas must be accurately known or measured ( 2 percent) to give acceptably accurate $\mathrm{C}-\mathrm{V}$ profiles.

- Schottky diode diameters between about 0.1 and $0.3 \mathrm{~mm}$ gave good yield and undistorted profiles; larger diodes produced erroneous and nonreproducible profiles. Area presents a tradeoff between higher ratio of peripheral edge to area for small areas and higher probability of overlaying a defect for large areas. The $0.13-\mathrm{mm}$ dots gave consistently good results, but 0.25-mm dots were sometimes poor (shorted). Lower defect density material 
might allow larger area, except that for larger areas, errors may result from the larger capacitance and lower diode $Q$.

- Diode breakdown voltages must be adequate to allow the implanted region to be depleted completely, or only partial profiles will be obtained.

- Silicon surfaces chemically cleaned prior to metallization gave better I-V characteristics and $\mathrm{C}-\mathrm{V}$ profiles than surfaces which had been $\mathrm{HF}$ etched.

- Gold on n-type silicon and aluminum or titanium on p-type silicon are good choices of Schottky metallizations; others may or may not be good and should be carefully investigated before being used.

- Aluminum and gold Schottky barriers should be allowed to "age" for one and three days, respectively, before profiling to ensure stable, reproducible $\mathrm{C}-\mathrm{V}$ profiles. Aging of aluminum and gold Schottky barriers was observed to occur as described in the literature; that is, the $\mathrm{I}-\mathrm{V}$ and $\mathrm{C}-\mathrm{V}$ characteristics changed with time and then stabilized. Aluminum Schottky barriers on clean (unetched) or cleaved silicon surfaces typically stabilize in a few hours to one day. Other metals like gold may require a few days. Once stabilized, I-V and $C-V$ characteristics were not observed to change over 24 months.

- Special treatments to improve Schottky barrier diodes: no improvement was observed when a shallow $p^{+}$-surface layer was implanted on a $p$-implanted surface. In particular, this layer did not give $\mathrm{C}-\mathrm{V}$ profile data closer to the surface. Annealing implanted surfaces (prior to Schottky metal deposition) in air instead of in dried argon or nitrogen resulted in poorer $I-V$ characteristics and in poor $C-V$ profiles. Heating surfaces with poor $I-V$ and/or $C-V$ characteristics had no effect on some implanted surfaces, and on others, 200 or $250^{\circ} \mathrm{C}$ caused noticeable improvement, while $100^{\circ} \mathrm{C}$ did not.

As a result of our study of thousands of Schottky diodes on surfaces implanted with a wide variety of ions, energies, and fluences, we have been able to construct the guide shown in figure 14 for values of zero-bias capacitance that will yield good $\mathrm{C}-\mathrm{V}$ profiles. This guide is principally based on diodes with diameter of $0.13 \mathrm{~mm}$. A significant feature of this guide is that the usable capacitance values decrease as the depth of the implanted profile increases. This occurs for deeper implants at roughly constant ion fluence. Higher fluences can be used at low energies (shallower penetration). The upper limits of fluence that we observed are roughly: 1 to $1.5 \times 10^{12} \mathrm{~cm}^{-2}$ for ions and energies that produce profiles that extend deeper than $3 \mu \mathrm{m} ; 1.5$ to $2.5 \times 10^{12} \mathrm{~cm}^{-2}$ for 1 to $3 \mu \mathrm{m}$; and 2 to $5 \times 10^{12}$ $\mathrm{cm}^{-2}$ as the depth decreases below $1 \mu \mathrm{m}$. These quoted fluences are for ions that produce full electrical activity. These doses may be divided by the electrical activation coefficient for cases of incomplete activation. 


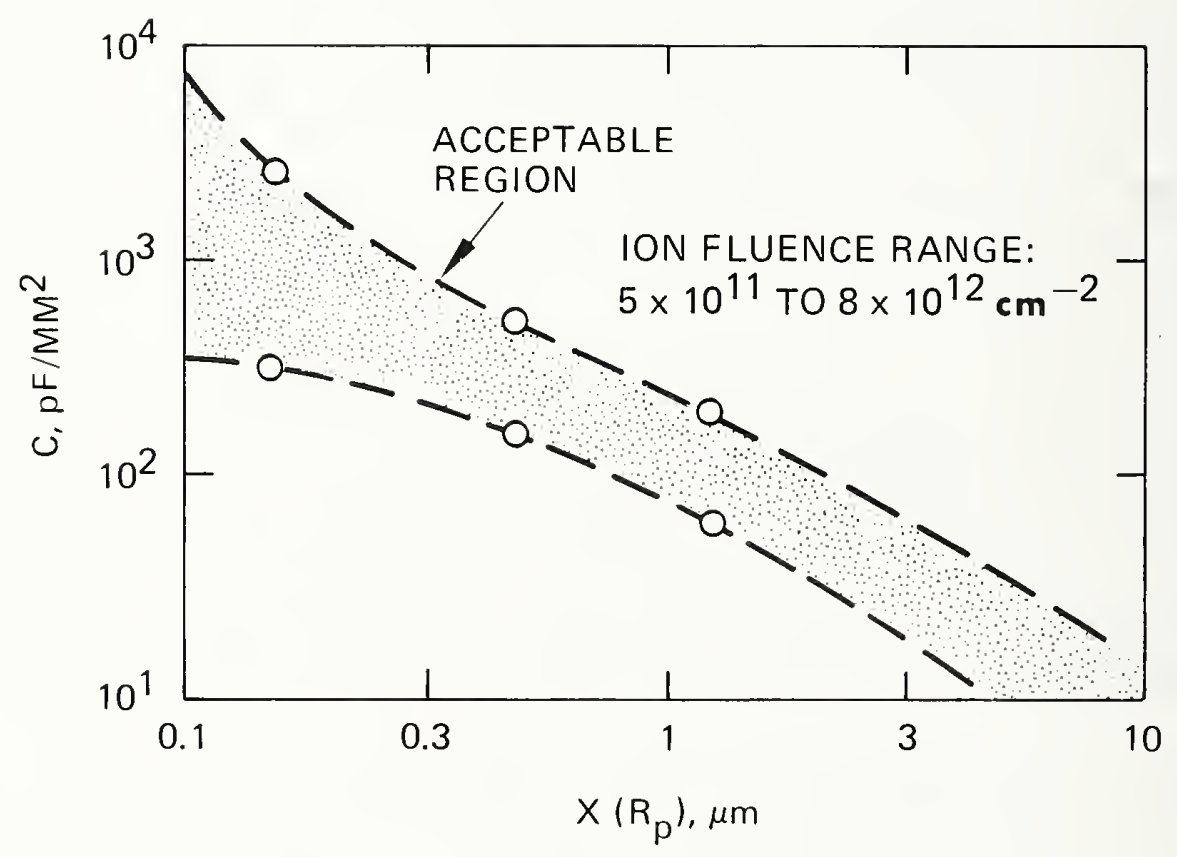

Figure 14. Capacitance values for good $\mathrm{C}-\mathrm{V}$ profiles of varying depth. 


\section{SAMPLE PREPARATION, IMPLANTATION, AND PROCESSING}

\section{1 Summary}

The following procedure has been developed and used to prepare and profile samples reproducibly using the differential $\mathrm{C}-\mathrm{V}$ technique with reverse-biased Schottky diodes.

Starting Material: Select 10 to $100 \Omega \cdot \mathrm{cm} n$ - or $p$-type silicon ( $n$ for $n$-type implants and $p$ for $p$-type implants) (see sec. 4.2).

Cleaning: Rinse with trichlorethylene, acetone, alcohol. Rinse with deionized water. Do not etch or cleave.

Formation of Back Contacts: n-type: Implant back surface with low-energy $n$ type dopant to make $n^{+}$layer $\left(\mathrm{e} \cdot \mathrm{g} \cdot\right.$, As $\left.{ }^{+}\right)$. p-type: Implant back surface with low-energy $p$-type dopant to make $\mathrm{p}^{+}$layer $\left(\mathrm{e} \cdot \mathrm{g} \cdot, \mathrm{B}^{+}\right.$or $\left.\mathrm{Al}^{+}\right)$.

Implantation: Implant desired dopant in front surface of sample, under desired conditions, such as in the random equivalent or in an aligned orientation $[19,57,58]$.

Anneal: To activate implanted dopant anneal in vacuum, in nitrogen from liquid nitrogen, or in argon for 20 to $30 \mathrm{~min}$ at the appropriate temperature for the implanted dopant or for a selected annealing study. Annealing studies are performed at this point by varying the annealing temperature for a group of pieces cut from the same implanted wafer.

Schottky Barrier Formation: Evaporate metal films about $100 \mathrm{~nm}$ thick over the implanted surface of silicon wafers to form Schottky metallization. Define arrays of dots 0.13 and $0.25 \mathrm{~mm}$ in diameter by a metal mask or by photolithography. For thermal evaporation of aluminum and gold, use deposition rates of about $10 \mathrm{~nm} / \mathrm{s}$ and vacuum conditions of about 2 to $6 \times$ $10^{-6}$ Torr during evaporation. For electron-beam evaporation, use a vacuum condition between $5 \times 10^{-8}$ and $2 \times 10^{-7}$ Torr and a deposition rate between 0.2 and $0.6 \mathrm{~nm} / \mathrm{s}$. (Film thicknesses in the electron-beam evaporation system could be controlled to $\pm 2 \mathrm{~nm}$.)

I-V Measurements: Measure the I-V characteristics of the Schottky diodes in order to determine three important qualities of each diode before $\mathrm{C}-\mathrm{V}$ profiles are measured. Accept only diodes which are not shorted, which have "hard" I-V characteristics, and which exhibit no significant leakage. Determine the value of voltaqe at the beginning of breakdown or determine that breakdown does not occur at the maximum voltage that will be used to obtain the $\mathrm{C}-\mathrm{V}$ profile; the maximum reverse-bias voltage that may he required to deplete through a deep implant may he as much as $100 \mathrm{~V}$.

C-V Measurements: Calculate $\mathrm{x}$ and $\mathrm{n}(\mathrm{x})$ calibrations using appropriate equations for the profiler being used. Calibrate the profiler recorder. Mount the sample. Make contact with the probe to give a stable capacitance reading. Raise the bias voltage to a level that brings the profile to the background level on the recorder. Switch the profiler to automatic sweep and record the $\mathrm{C}-\mathrm{V}$ plot as the reverse-bias voltage decreases to zero. 
Alternatively, plot the profile for increasing reverse-bias voltage. (Forward and reverse profiles agree if the voltage sweep rates are sufficiently slow that no distortions occur. The increasing voltage technique is especially useful when the implanted profile is very deep and there is a risk of breaking down the diode before the depletion region is driven entirely through the distribution. Measuring the profile in the increasing voltage mode may allow a profile to be obtained up to the breakdown voltage, whereas increasing the voltage to the high breakdown voltage first may cause an irreversible voltage breakdown change in the diode.)

\section{2 Material}

There are many sources of good silicon today. Therefore, it is probably useful only to state what material was found to be satisfactory for the experimental work described here. While some material was used from other sources, especially for particular crystallographic orientations, most of the work was done using (low-oxygen) float-zone-refined silicon. The material was chem-mechanically polished to within \pm 1 deg of the (111) surface with a [110] flat and had fewer than 300 etch pits per square centimeter.

The older literature estimates that a natural oxide less than $2.5 \mathrm{~nm}$ thick exists on such surfaces; newer literature estimates it to be about 0.5 or 1 nm. (See sec. 3.3.) We performed a measurement using Rutherford backscattering to determine the approximate amount of oxygen and other observable heavier elements on the surface of the material being used. The results for the material described above were that the amount of oxygen on the surface was $\sim 3 \times 10^{15} \mathrm{~cm}^{-2}$, which is compatible with the 0.5 or $1 \mathrm{~nm}$ number, and no heavier elements were observed within the detection sensitivity.

\section{DATA ANALYSES}

\subsection{The Kennedy-O'Brien Correction}

The Kennedy-O'Brien correction [3] is a modification applied to the measured majority carrier density $n(x)$ to correct it to the true ionized impurity density distribution $n_{D}(x)$. This correction is given as:

$$
n_{D}(x)=(x)+\frac{k T \varepsilon}{e^{2}} \frac{d}{d x}\left[\frac{1}{n(x)} \frac{d n(x)}{d x}\right] \text {. }
$$

At the peak of carrier density profiles where $R_{p}$ is measured, there is essentially no correction to be made for values of $R_{p}$ or $R_{m}$. The correction has a negligible effect on values of $\Delta R_{p}$ (or $\sigma$ ) if these are measured above 10 percent of the peak density, as they usually are.

The magnitude of the correction is illustrated in figures 15 and 16, for profiles of various depths and shapes. The magnitude of the correction depends on the magnitude, the slope, and the second derivative of the distribution [see eq (19)]. The correction is seen to be small for deep 


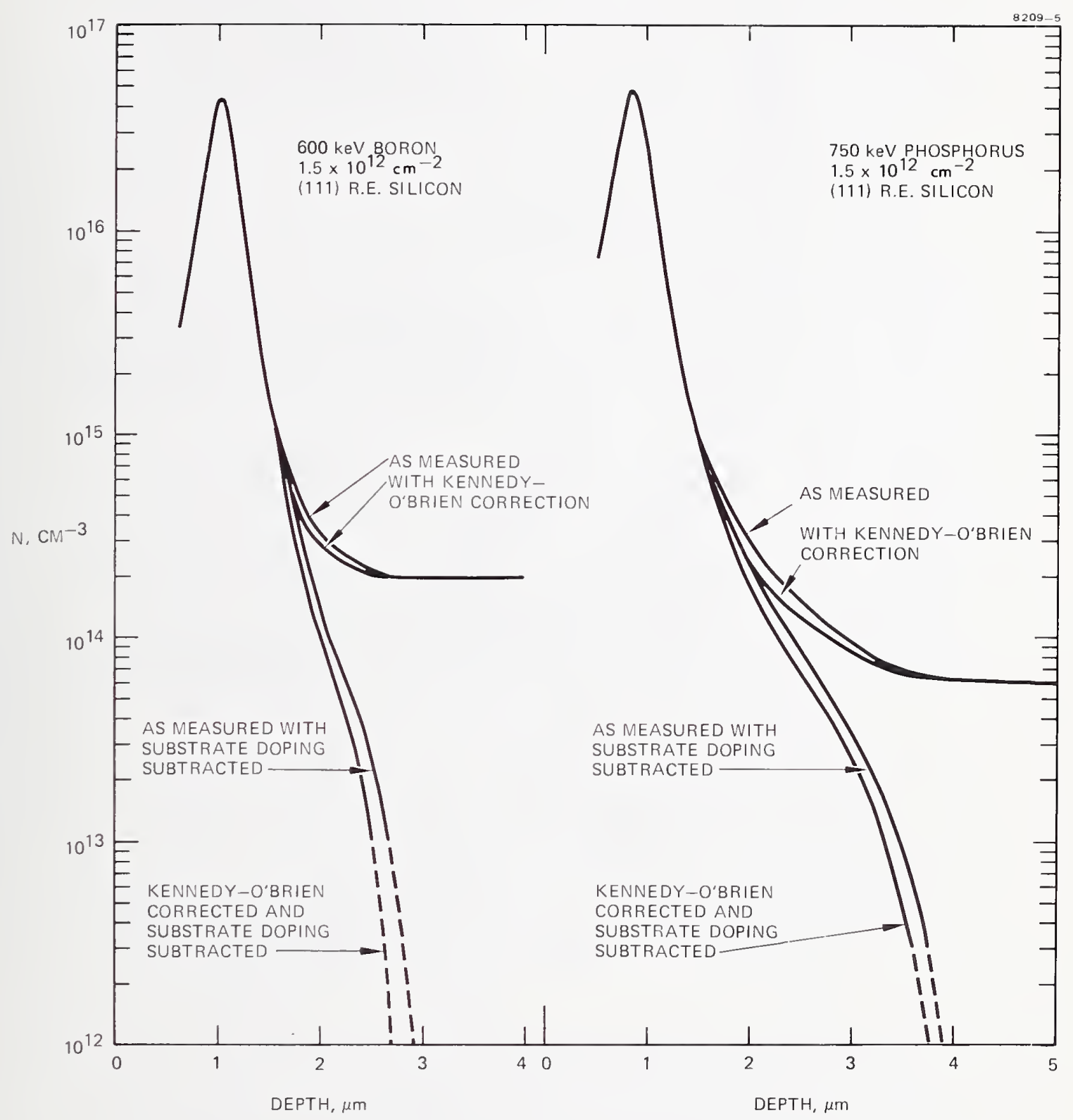

Figure 15. Typical deep $C-V$ profiles showing effects of Kennedy-O'Brien correction and of correction for substrate dopant level. 


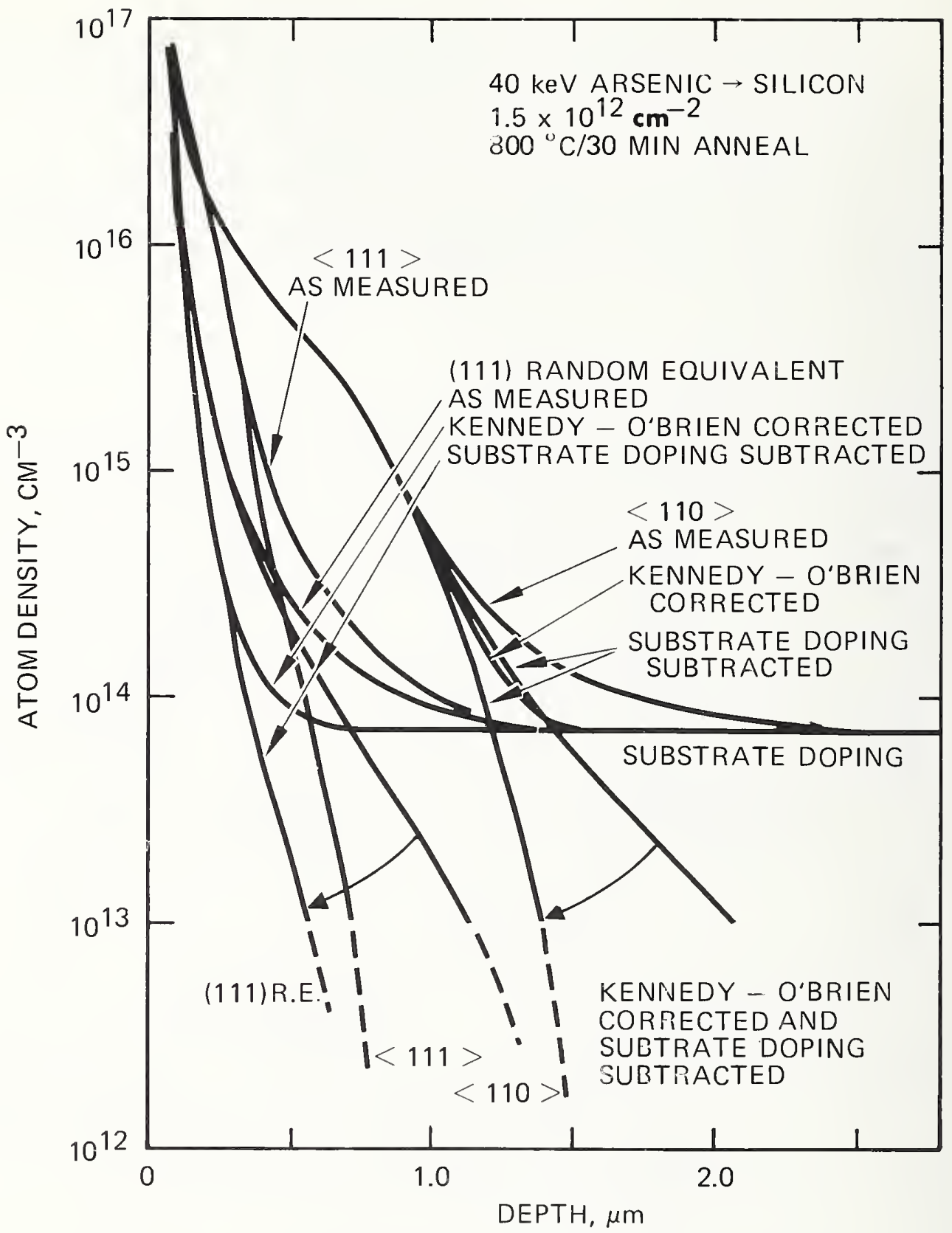

Figure 16. Typical shallow $\mathrm{C}-\mathrm{V}$ profiles showing effects of Kennedy-O'Brien correction and of correction for substrate dopant level. 
profiles (fig. 15); it is less than 1 percent in the depth at $10^{15} \mathrm{~cm}^{-3}$, and varies from 4 to 6 percent in the depth from the mid $10^{14} \mathrm{~cm}^{-3}$ range to $10^{12}$ $\mathrm{cm}^{-3}$. These errors in depth are less than the experimental error. The corresponding errors in the total implanted distribution (the areas between the as-measured and corrected profiles) are less than 0.3 percent. The magnitude of the error increases as the profiles become shallower. An example of the effect on profiles of different shapes is illustrated in figure 16 by showing the as-measured and corrected profiles for $40-\mathrm{keV}$ arsenic in the (111) random equivalent, $\langle 111\rangle$ channeled, and $\langle 110\rangle$ channeled orientations. For the $\langle 110\rangle$ channeled case, where the second derivative is negative (above $10^{15} \mathrm{~cm}^{-3}$ ), the correction is negligible; where the second derivative is positive (below $\sim 5 \times 10^{14} \mathrm{~cm}^{-3}$ ), the correction is progressively larger with increasing depth, causing a significant correction to the profile and being $\sim 13$ percent in depth at $10^{14} \mathrm{~cm}^{-3}$ and increasing to $\sim 40$ percent at $10^{13} \mathrm{~cm}^{-3}$. For the $\langle 111\rangle$ channeled profile, the correction in depth begins to be significant at $3 \times 10^{15} \mathrm{~cm}^{-3}$, is 10 percent at $1 \times 10^{15}$ $\mathrm{cm}^{-3}$, is 35 percent at $10^{14} \mathrm{~cm}^{-3}$, and is $\sim 50$ percent at $10^{13} \mathrm{~cm}^{-3}$. For the (111) random equivalent orientation, the entire profile is corrected from its beginning at $3 \times 10^{16} \mathrm{~cm}^{-3}$; the correction is $\sim 8$ percent in depth at $1 \times 10^{16}$ $\mathrm{cm}^{-3}$, is $\sim 35$ percent at $1 \times 10^{15} \mathrm{~cm}^{-3}$, is 60 percent at $1 \times 10^{14} \mathrm{~cm}^{-3}$, and is 80 percent at $1 \times 10^{13} \mathrm{~cm}^{-3}$. The corresponding errors in the total implanted distribution are 0.3 percent for the $\langle 110\rangle$ channeled profile, 0.9 percent for the $\langle 111\rangle$ channeled profile, and $\rangle 5$ percent for the (111) random equivalent profile. The corresponding profile for 20-kev arsenic in the (111) random equivalent orientation after the correction and after substrate dopant level subtraction is zero everywhere in the measured region; that is, it does not exist deeper than $0.1 \mu \mathrm{m}$ with a density above about $10^{14} \mathrm{~cm}^{-3}$.

In summary, the Kennedy-O'Brien correction is small for deep profiles and becomes increasingly significant as profiles become shallower. The correction is greater when the second derivative is negative, such as it is for tails on random equivalent implants, than for when it is positive, such as it usually is for channeled profiles. The correction decreases as the density increases; it is significant above $10^{15} \mathrm{~cm}^{-3}$ only for profiles less than $\sim 0.5 \mu \mathrm{m}$ in depth. The correction can alter shallow $(<\sim 0.5 \mu \mathrm{m}) \mathrm{C}-\mathrm{V}$ profiles drastically and should always be applied in those cases.

\subsection{Background Subtraction}

Ordinarily, the differential C-V profiling technique is used to measure a carrier density or dopant profile in a semiconductor material with a base dopant level in the $10^{14}$ to $10^{15} \mathrm{~cm}^{-3}$ range. This background dopant level is ordinarily recorded as part of the differential $\mathrm{C}-\mathrm{V}$ profile and can be easily subtracted from the total recorded profile after the Kennedy-O'Brien correction has been made. This is illustrated in figures 15 and 16 for implanted profiles in n-type and $p$-type silicon with hackground dopant levels of $0.6 \times 10^{14} \mathrm{~cm}^{-3}$ and $2.0 \times 10^{14} \mathrm{~cm}^{-3}$, respectively. It is seen that the resulting implanted profiles can be extended to $10^{13} \mathrm{~cm}^{-3}$, or even to $\sim 10^{12}$ $\mathrm{cm}^{-3}$, by the subtraction of the background dopant level. The accuracy of the curves in the low $10^{13} \mathrm{~cm}^{-3}$ and $10^{12} \mathrm{~cm}^{-3}$ decades is progressively reduced. 


\section{COMPARISONS OF $\mathrm{C}-\mathrm{V}$ AND SIMS PROFILES*}

\subsection{The SIMS Technique and Experimental Accuracies}

The general SIMS technique is described adequately in the literature [59, 60]. A comprehensive discussion of the considerations that affect the accuracy of SIMS measurements of implanted depth distributions, including ion beam, environment, sputtering process, and target surface and bulk effects, is given by Hofker [18]. In the results reported here, essentially the same type of experimental equipment, techniques, and parameters were used as Hofker used. In brief, an oxygen ion beam was used, typically of 5-keV energy and 1- to 5- $\mu \mathrm{A}$ current; the secondary ions recorded were ${ }^{6}, 7 \mathrm{Li}^{+}$, ${ }^{9} \mathrm{Be}^{+}, 10, \mathrm{Il}_{\mathrm{B}^{+}}, \mathrm{Al}^{+}, \mathrm{AsO}^{-}, \mathrm{SbO}^{-}, \mathrm{etc}$; the environment pressure was $\sim 3 x$ $10^{-7}$ Torr; data are ignored for the first $\sim 10 \mathrm{~nm}$ of sputtered surface; and depth scales are calibrated by surface profilometer measurements of the sputtered crater depths in the center of the craters, combined with monitoring of the sputtering rate. The secondary ions were collected from only the central region of the sputtered crater and several sputtering runs were compared for reproducibility for each implanted region, both for profile and for crater depth. Hofker indicates that crater depth measurements are accurate to within about 3 percent. Reproducibility from measurement-tomeasurement is about \pm 5 percent. Our results would indicate a reproducibility of \pm 5 to 10 percent. Crater profiles are flat within \pm 10 percent in the region from which the secondary ions are collected.

The values of atom density for SIMS depth distributions are determined as follows. For profiles that have not redistributed, the area integral of the profile is equated to the implanted ion fluence. The measured ion fluence may be accurate to within 1 to 5 percent if careful secondary suppression techniques are employed [61], and may be more typically in error by 10 to 20 percent. Thus, SIMS absolute density measurements may be accurate within 5 percent, or 10 to 20 percent. The accuracy within a profile varies with the total number of counts at each depth compared with the background level and counting statistics. For our measurements, the statistical variations at two selected representative values were \pm 1000 counts at 50,000 counts or 2 percent and \pm 20 counts at 60 counts or 33 percent. This latter value is representative of the background region or lowest atom density portion of a sIMS profile.

\subsubsection{Experimental Errors}

For the SIMS data, all depths are accurate to within \pm 7 percent or $30 \mathrm{~nm}$, whichever is larger. The \pm 7 percent is determined by the reproducibility of crater depths measured by a surface profilometer; the absolute accuracy of the measurements is probably $30 \mathrm{~nm}$. The relative error in atom density is \pm 2 percent at 50,000 counts (about the fourth decade of SIMS data) and \pm 30 percent at 50 counts (about the first decade of SIMS data) from SIMS counting statistics. The absolute error is \pm 2.5 percent, determined by the accuracy

* The SIMS data reported here were obtained by Dr. J. Comas of The Naval Research Laboratories. This work was supported in part by ARPA through NBS Orders 708041 and 801846. 
of the ion fluence measurement using a current integrator and a good secondary suppression geometry [61].

For the $C-V$ profiles, the rms error in atom density $[n(x)]$ is 7 percent; in depth $(x)$, it is 3 percent, determined from analysis of the $C-V$ profiler equations and the required experimental measurements. The Kennedy-O'Brien correction (sec. 5.1) causes a foreshortening in $\mathrm{x}$ of a maximum of about 3 percent in the low $10^{14} \mathrm{~cm}^{-3}$ atom density range on the deep side of the profiles, decreasing to 0 percent at the peak of the profile, for slopes that are typical of random equivalent or channeled implanted depth distribution.

Implantation energy in this work was accurate to about 2 percent by periodic calibration of the implanter with a 1-percent, 300-kV voltmeter. The major effect of this 2 -percent error is in the absolute value of ion range; it has little effect on straggle or profile shape parameters. Implanted ion fluences are 2 to 3 percent accurate in absolute value and reproducible to better than 1 percent using current integrators shown to have adequate response to implantation conditions [61].

\subsection{Comparison of SIMS Atom and C-V Carrier Distributions}

The sensitivities of the SIMS and $\mathrm{C}-\mathrm{V}$ techniques for beryllium in silicon make the Be-Si system an ideal vehicle for comparison of depth distribution of atoms measured by SIMS and the associated carrier electrical activity (acceptor in this case) measured by differential $\mathrm{C}-\mathrm{V}$ profiling. The sensitivities are such as to allow the two techniques to be used on the same or identically implanted samples over a small range of ion fluence from about $1 \times 10^{12}$ to $5 \times 10^{12} \mathrm{~cm}^{-2}$ [62]. The approximately 40-percent electrical activation of acceptor activity for beryllium in silicon allows the beryllium fluence to be as high as $5 \times 10^{12} \mathrm{~cm}^{-2}$ for 40 to $600 \mathrm{keV}$ for the $\mathrm{C}-\mathrm{V}$ technique. The sensitivity of positive-ion-mode sIMs for beryllium allows SIMS profiles to be measured for densities as low as $\sim 10^{13} \mathrm{~cm}^{-3}$ (near $10^{-10}$ parts) or for a corresponding fluence down to $10^{12} \mathrm{~cm}^{-2}$.

Normalized SIMS and $\mathrm{C}-\mathrm{V}$ profiles for $100-\mathrm{keV}$ beryllium in random equivalent silicon are shown in figure 17. The $\mathrm{C}-\mathrm{V}$ acceptor distributions are for $500^{\circ} \mathrm{C}$ annealing temperature and an ion fluence of $3 \times 10^{12} \mathrm{~cm}^{-3}$. Two unannealed SIMS atom distributions are shown for comparison. The lower fluence sImS data are seen to agree with the $\mathrm{C}-\mathrm{V}$ acceptor distribution on the deep side of the profile. The higher fluence sIms curve is less deep. Little change occurs in the SIMS distribution after $500^{\circ} \mathrm{C}$ annealing [62].

The following conclusions are drawn from these and other similar data: 1) At $100-\mathrm{keV}$ ion energy, the $\mathrm{C}-\mathrm{V}$ electrical profile agrees with the SIMS atom profile on the deep side for the comparably low fluence. 2) The SIMS profile for the low fluence is relatively wider on the deep side (deeper) because of the greater effect of channeling that results from scattering in the random equivalent orientation of crystalline silicon for densities less than about one order of magnitude below the maximum. For some fluence between $10^{13}$ and $5 \times 10^{15} \mathrm{~cm}^{-2}$, the channeling tail effect saturates because damage blocks the channels. 3) The SIMS and $C-V$ profiles yield about the same value of half width $\left(\Delta R_{p}\right)$ at $e^{-1 / 2} N_{\max }$. 4) The $C-V$ curve is somewhat higher than SIMS curves on the surface side of the distribution. This is attributed to 


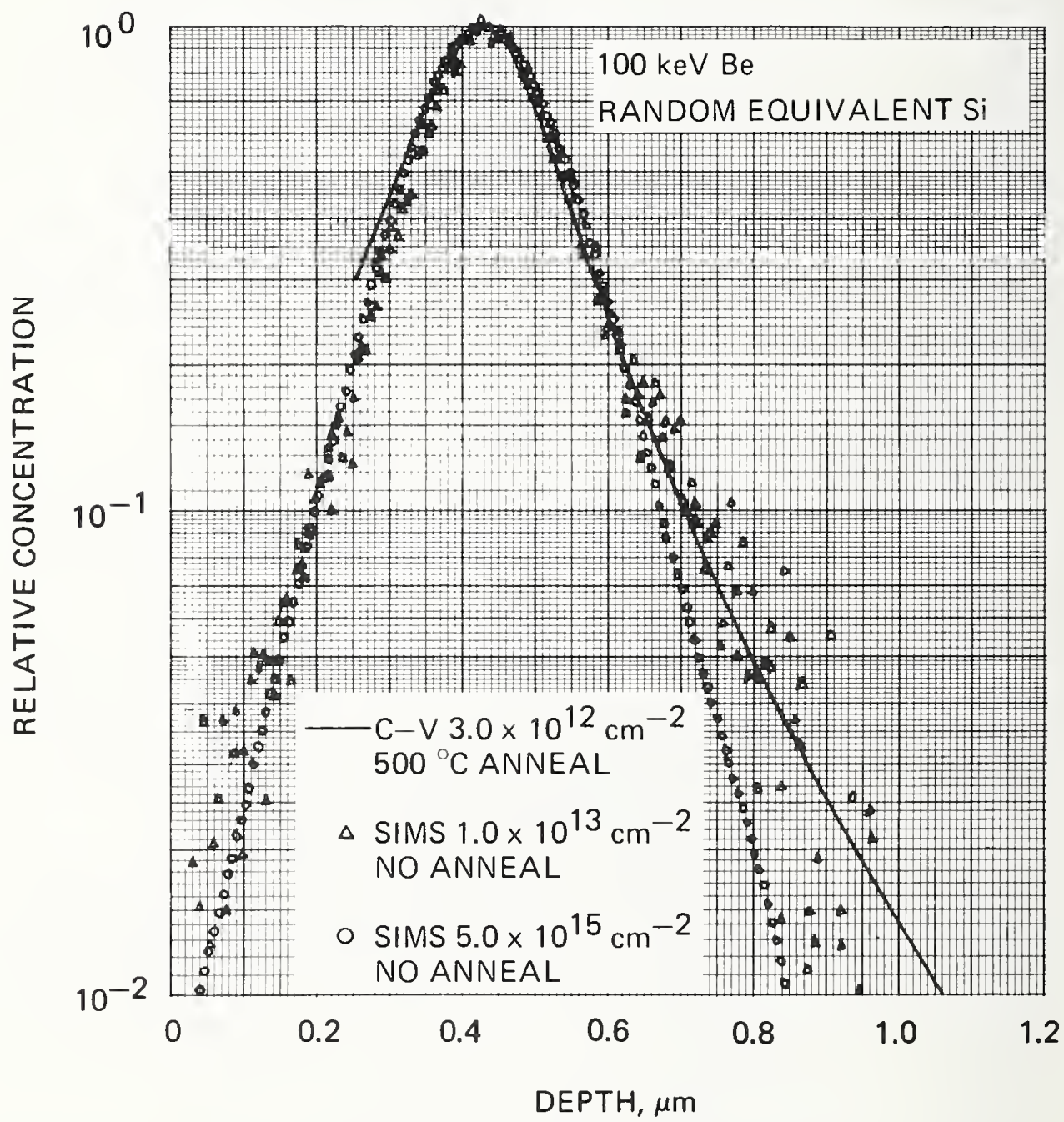

Figure 17. SIMS and $\mathrm{C}-\mathrm{V}$ profiles for 100-keV beryllium in silicon. 
the $\mathrm{C}-\mathrm{V}$ profiling measurement technique; as the surface is approached, the value of capacitance measured by the system increases to its maximum value and the $Q$ of the diode approaches the region where some error may be introduced that increases the value of the density artificially when high resistivity silicon is used to give good information on the deep side. The additional use of a lower resistivity substrate would give better nearsurface data, at the expense of data for lower density. The use of a lower ion fluence would produce a lower zero-bias capacitance and would also improve this situation. This effect is seen to be small or negligible where $\Delta R_{p}$ is usually measured. The concept of a $\Delta R_{p}$ that is associated with a Gaussian distribution is seen to be rather inappropriate for beryllium depth distributions because they are not Gaussian; both C-V and SIMS distributions become continuously wider than Gaussian as the density decreases, corresponding to a fourth moment or kurtosis.

Similar curves for $300-\mathrm{keV}$ boron are shown in figure 18 to allow a comparison between beryllium and boron, a commonly used ion in silicon. Annealing at $800^{\circ} \mathrm{C}$ is done to ensure full electrical activation at these low ion fluences. The $\mathrm{C}-\mathrm{V}$ profile for the much lower fluence agrees with the unannealed SIMS profile on the deep side but is again slightly higher on the surface side, such as to agree roughly with the similarly annealed SIMS profile. These profiles imply that $800^{\circ} \mathrm{C}$ annealing causes a movement of boron $\sim 50$ to $75 \mathrm{~nm}$ in each direction for a fluence of $3 \times 10^{14} \mathrm{~cm}^{-2}$, but not for $1.5 \times 10^{12}$ $\mathrm{cm}^{-2}$. Independent measurements have shown that no diffusion occurs at $800^{\circ} \mathrm{C}$ for $1.5 \times 10^{12} \mathrm{~cm}^{-2}$ boron implants. This suggests that the movement is implantation-damage-associated. The deep side curves are seen to have opposite curvature for the two annealing conditions. The widths $\left(\Delta R_{p}\right)$ are again the same.

\section{CONCLUSIONS AND SUMMARY}

Ion-implanted depth distributions can be obtained from $\mathrm{C}-\mathrm{V}$ measurements for the columns III and $V$ dopants in silicon and for other ions that produce donor or acceptor electrical activity, such as columns II and VI elements. The range of ion energy that can be studied corresponds to that which penetrates about $150 \mathrm{~nm}$ (about $10 \mathrm{keV}$ for light ions, up to about $80 \mathrm{keV}$ for heavy ions) to at least 1 or $2 \mathrm{MeV}$.

We observe that the depth profiles for light ions exhibit distinct channeling peaks and only small scattering tails. We observe that as the ion mass increases, the scattering-channeled tails increase significantly and the channeling peaks become indistinct and finally disappear. Our measured ranges $R_{p}$ agree quite well with the LSS calculations of Brice (1971) and Johnson and Gibbons (1970) for nearly all ions usually within a few percent. The range straggles calculated by Brice are larger than those of Johnson and Gibbons and our measured $\Delta R_{p}$ 's are up to 50 percent larger still than the values of Brice in agreement with the discussion of Kalbitzer and Detzman [63]. 


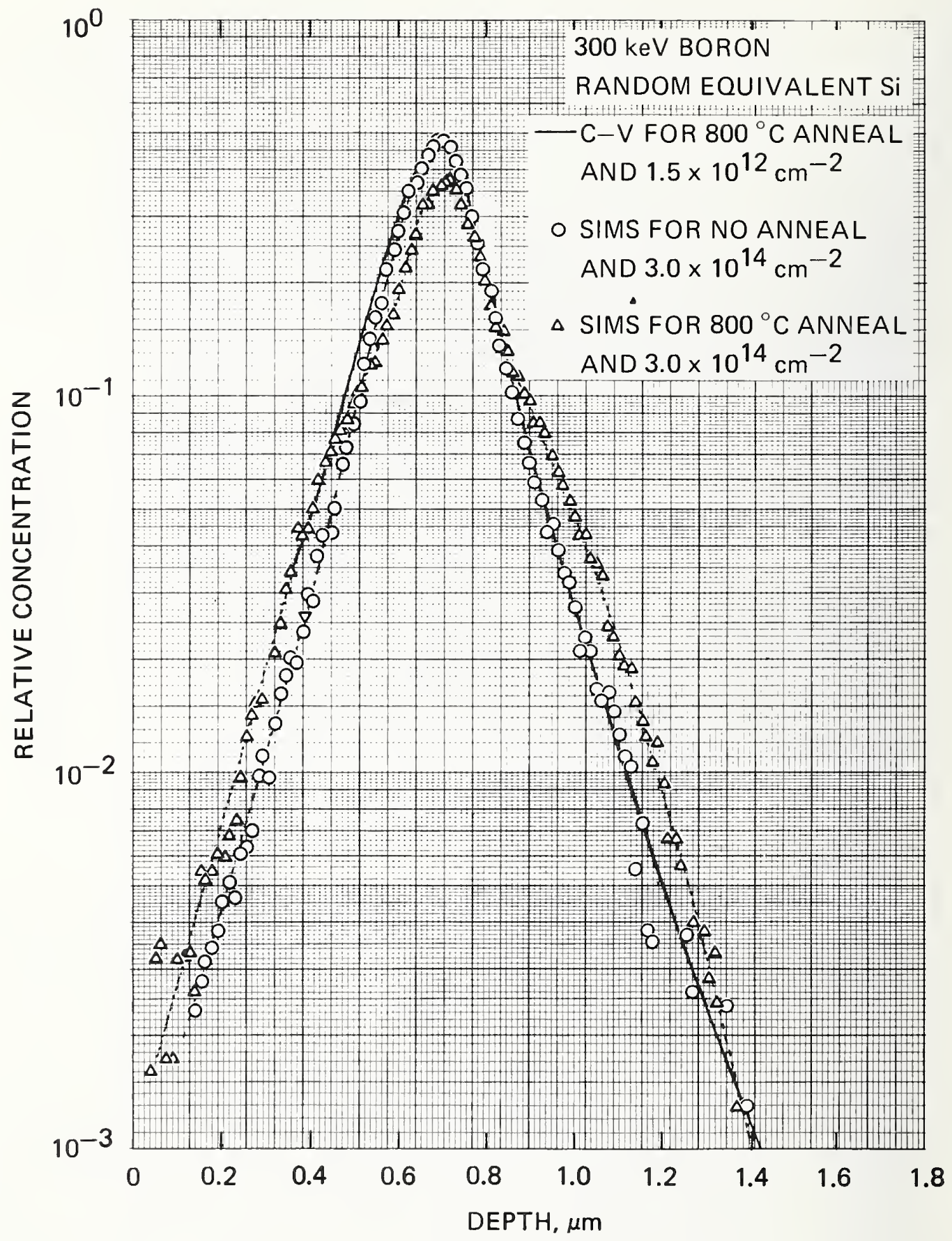

Figure 18. SIMS and $\mathrm{C}-\mathrm{V}$ profiles for $300-\mathrm{keV}$ boron in silicon. 
7.1 What Can Be Measured By Differential C-V Profiling

Our extensive investigations during this program have shown that differential $C-V$ profiling of the electrical activity in ion-implanted semiconductor layers can be used to study a wide variety of characteristics of the implantation and annealing process steps, including those listed below.

- Annealing Activation: the depth distribution and total activation efficiency; threshold temperatures for the onset of electrical activation and electrical activity as a function of annealing temperature; annealing time requirements at a given temperature.

- Thermal Redistribution: changes in the depth profile of electrical activity as annealing progresses.

- Values of Profile Parameters: $R_{p}$ and $\Delta R_{p}$ for Gaussian depth distribution; $R_{m}, \gamma_{1}$, and $\beta_{2}$, for non-Gaussian depth distributions; $R_{C}, \sigma_{C}, \gamma_{1 C}$, and $B_{2 C}$, the first, second, third, and fourth moments of channeled peaks; the fraction of ions contributing to the channeled, dechanneled, random, and (sometimes) quasi-random fractions of an aligned implantation depth distribution.

- Range-Energy Curves: the depth distributions of electrical activity as a function of ion energy and parameters such as peak depth $\left(R_{m}\right)$ versus energy, $\Delta \mathrm{R}_{\mathrm{p}}$ versus energy, $\mathrm{R}_{\mathrm{C}}$ versus energy, etc.

- Stopping Power Values: from the range-energy curves.

7.2 Limitations on the $C-V$ Profiling Technique

There are distinct limitations on the ranges of validity of the technique, discussed in detail in the body of this report. The ranges of carrier density and depth in which the technique can yield reliable results are:

- Carrier Density: $\sim 10^{13}$ to mid $10^{17} \mathrm{~cm}^{-3}$. Densities below $10^{13} \mathrm{~cm}^{-3} \mathrm{can}$ be recorded for high resistivity substrates (such as semi-insulating material), but they are of questionable validity due to the small values of $Q$ for these conditions. The lower part of the $10^{13} \mathrm{~cm}^{-3}$ decade usually results from subtraction of the background dopant density and therefore becomes less accurate than the higher densities.

- Depth: 80- to 100-nm minimum for shallow implants, successively greater depths for successive deeper implants; the maximum depth has no particular limit, but a practical limit is imposed by the breakdown voltage of the diode under study. Good diode technoloqy can make this value high. We have observed breakdown voltages of 100 to $120 \mathrm{~V}$ and corresponding implanted profiles up to $10 \mu \mathrm{m}$ deep. 
1. Thomas, C. O., Kahng, D., and Manz, R. C., Impurity Distribution in Epitaxial Silicon Films, J.Electrochem. Soc. 109, 1055-1061 (1962).

2. Amron, I., Errors in Dopant Concentration Profiles Determined by Differential Capacitance Measurements, Electrochem. Tech. 5, 94-97 (1967).

3. Kennedy, D. P., and O'Brien, R. R., On the Measurement of Impurity Atom Distributions in Silicon by the Differential Capacitance Technique, IBM J. Res. Dev. 13, 212-214 (March 1969); and Kennedy, D. P., Murley, P. C., and Kleinfelder, W., On the Measurement of Atom Distributions in Silicon by the Differential Capacitance Technique, IBM J. Res. Dev. 12, 399-408 (September 1968).

4. Moline, R. A., Ion Implanted Phosphorus in Silicon: Profiles Using C-V Analysis, J. Appl. Phys. 42, 3553-3558 (1971).

5. Seidel, T. E., Distribution of Boron Implanted Silicon, Proc. 2nd Intemat. Conf. on Ion Implantation in Semiconductors, May 24-28, 1971, Garmisch-Partenkirchen, Germany, pp. 47-57.

6. Reddi, V. G. K., and Sansbury, J. D., Channeling and Dechanneling of Ion-Implanted Phosphorus in Silicon, J. Appl. Phys. 44, 2951-2963 (1973).

7. Wu, C. P., Douglas, E. C., and Mueller, C. W., Limitations of the CV Technique for Ion-Implanted Profiles, IEEE Trans. Electron Devices ED-22, 319-329 (1975).

8. Johnson, W. C., and Panousis, P. T., The Influence of Debye Length on the $\mathrm{C}-\mathrm{V}$ Measurement of Doping Profiles, IEEE Trans. Electron Devices $\underline{E D-18}, 965-973$ (1971).

9. Verjans, J., and van Overstraeten, R. J., Measurement of the Electrical Impurity Profile of Implanted Ions, Using the Pulsed MoS C-V Technique, Solid-State Electron. 18, $911-916$ (1975).

10. Lehovec, K., C-V Analysis of a Partially Depleted Semiconducting Channel, Appl. Phys. Lett. 26, 82-84 (1975).

11. Lindhard, J., Scharff, M., and Schiфtt, H. E., Range Concepts and Heavy Ion Ranges, Notes on Atomic Collisions II, Mat. Fys. Medd. Dan. Vid. Selsk. 33 (14) (1963).

12. Gibbons, J. F., Johnson, w. S., and Mylroie, S. W., Projected Range Statistics Semiconductors and Related Materials (Halstead Press, John Wiley \& Sons, 1975).

13. Brice, D. K., Spatial Distribution of Ions Incident on a Solid Target as a Function of Instantaneous Energy, Sandia Labs Report SC-RR-71-9599, Albuquerque (1971); Appl. Phys. Lett. 16, 103-106 (1970); and 
Brice, D. K., Ion Implantation Range and Energy Deposition Distributions, volume 1, High Incident Ion Energies, p. 572 (IFI/Plenum, New York, 1975).

14. Schiфtt, H. E., Projected Ranges of Light Ions in Heavy Substrates, Can. J. Phys. 46, 449-453 (1968); Range-Energy Relations for LowEnergy Ions, Mat. Fys. Medd. Dan. Vid. Selsk 35 (9), 3-20 (1966); and Approximations and Interpolation Rules for Ranges and Range Stragglings, Radiat. Eff. 6, 107-113 (1970).

15. Winterbon, K. B., Ion Implantation Range and Energy Deposition Distribution, Vol. 2 (Plenum Press, New York, 1975); and Calculations of Implanted Ion Range and Energy-Deposition Distributions: ${ }^{11} \mathrm{~B}$ in $\mathrm{Si}$, Radiat. Eff. 30, 199-206 (1976).

16. Yudin, V. V., Ranges and Standard Deviations of Implanted Ions, Appl. Phys. 15, 223-228 (1978).

17. Wilson, R. G., Range-Energy Curves for Ions in Compound Semiconductors and Insulators and in Beam Resist Materials, Hughes Research Laboratories (July 1969) (unpublished).

18. Hofker, W. F., Implantation of Boron in Silicon, Phillips Research Reports Supplements, No. 8 (1975).

19. Wilson, R. G., Dunlap, H. L., Jamba, D. M., and Myers, D. R., Semiconductor Measurement Technology: Angular Sensitivity of Controlled Implanted Doping Profiles, NBS Spec. Publ. 400-49 (November 1978).

20. Schulz, M., Determination of Deep Trap Levels in Silicon Using Ion Implantation and C-V Measurements, Appl. Phys. 4, 225-236 (1974).

21. Hurrle, A., and Schulz, M., Anomalous Outdiffusion of Beryllium Implanted into Silicon, Inst. Phys. Conf. Ser. 23, 474-480 (1975).

22. Moline, R. A., and Reutlinger, G. W., Phosphorus Channeled in Silicon: Profiles and Electrical Activity, Second Intemat. Conf. Ion Implantation in Semiconductors, May 24-28, 1971, Garmisch-Partenkirchen, pp. 58-69.

23. Albers, J. H., Ehrstein, J. R., Wilson, R. G., and Comas, J., Comparison of SIMS, C-V, and Spreading Resistance Profiles of Boron Implants in Silicon, Extended Abstracts, spring Meeting of the Electrochemical Society, Vol. 80-1, pp. 496-498 (ECS, Princeton, New Jersey).

24. Roberts, G. I., and Crowell, C. R., Capacitive Effects of Au and Cu Impurity Levels in Pt-N Type Silicon Schottky Barriers, Solid State Electron. 16, 29-38 (1973).

25. Nicollian, E. H., and Goetzberger, A., The Si-SiO 2 Interface Electrical Properties as Determined by the Metal-Insulator-Silicon Conductance Technique, Belz Syst. Tech. J. 46, 1055-1133 (1967). 
26. Nicollian, E. H., Goetzberger, A., and Lopez, A. D., Expedient Method of Obtaining Interface state Properties from MIS Conductance Measurements, Solid State Electron. 12, 937-944 (1969).

27. Copeland, J. A., Technique for Directly Plotting the Inverse Doping Profile of Semiconductor Wafers, IEEE Trans. Electron Devices ED$16,445-449$ (1969).

28. Baxandall, P. J., Colliver, D. J., and Fray, A. F., An Instrument for the Rapid Determination of Semiconductor Impurity Profiles, J. Phys. E4, 213-221 (1971).

29. Gordon, B. J., Stover, H. L., and Harp, R. S., A New Impurity Profile Plotter for Epitaxy and Devices, C. P. Marsden, Ed., NBS Spec. Publ. 337 pp. 273-284 (November 1970).

30. Anderson, C. L., Baron, R., and Crowell, C. R., Variable Frequency Automatic Capacitance/Conductance System for Impurity Profiling and Deep Level Determination, Rev. Sci. Instmum. 47, 1366-1376 (1976).

31. Miller, G. L., A Feedback Method for Investigating Carrier Distributions in Semiconductors, IEEE Trans. Electron Devices ED-19, 1103-1108 (1972).

32. Buehler, M. G., Peripheral and Diffused Layer Effects on Doping Profiles, IEEE Trans. Electron Devices ED-19, 1171-1178 (1972).

33. Grimshaw, J. A., and Osborne, D. N., Charge Neutrality in Semiconductors with Implanted Impurity Profiles, Solid-State Electron. 14, 603-611 (1971).

34. Wasserstrom, E., and McKenna, J., The Potential Due to a Charged Metallic Strip on a Semiconductor Surface, Bell Syst. Tech. J. 49 , 853-877 (1970).

35. Lehovec, K., Determination of Impurity and Mobility Distributions in Epitaxial Semiconducting Films on Insulating Substrate by $\mathrm{C}-\mathrm{V}$ and $\mathrm{Q}-\mathrm{V}$ Analyses, Appl. Phys. Letters 25, 279-281 (1974).

36. Bardeen, J., Surface States and Rectification at a Metal-Semiconductor Contact, Phys. Rev. 71, 717-727 (1947).

37. Gobeli, G. W., and Allen, F. G., Surface Measurements on Freshly Cleaved Silicon pn Junctions, J. Phys. Chem. Solids 14, 23-26 (1960).

38. Allen, F. G., and Gobeli, G. W., Work Function, Photoelectric Threshold, and Surface States of Atomically Clean Silicon, Phys. Rev. 127, 150-158 (1962).

39. Goodman, A. M., Metal-Semiconductor Barrier Height Measurements by the Differential Capacitance Method One Carrier System, J. App Z. Phys. 34, 329-338 (1963). 
40. Archer, R. J., and Atalla, M. M., Metal Contacts on Cleaved Silicon Surfaces, Ann. N.Y. Acad. Sci. 101, 697-708 (1963).

41. Spitzer, W. G., and Mead, C. A., Barrier Height Studies on MetalSemiconductor Systems, J. Appl. Phys. 34, 3061-3069 (1963).

42. Crowell, C. R., Shore, H. B., and LeBate, E. E., Surface States and Interface Effects in Schottky Barriers at $n$-Type Silicon Surfaces, $J$. Appl. Phys. 36, 3843-3852 (1965).

43. Crowley, A. M., and Sze, S. M., Surface States and Barrier Height of Metal-Semiconductor Systems, J. Appl. Phys. 36, 3213-3220 (1965).

44. Crowell, C. R., and Sze, S. M., Current Transport in Metal-Semiconductor Barriers, Solid-State Electron. 9, 1035-2048 (1966).

45. Turner, M. J., and Rhoderick, E. H., Metal-Silicon Schottky Barriers, Solid-State Electron. 11, 291-300 (1968).

46. Crowell, C. R., and Roberts, G. I., Surface State and Interface Effects on the Capacitance-Voltage Relationship in Schottky Barriers, $J$. Appl. Phys. 40, 3726-3730 (1969).

47. Archer, R. J., and Yep, T. O., Dependence of Schottky Barrier Height on Donor Concentration, J. Appl. Phys. 41, 303-311 (1970).

48. Schulz, M., Deep Trap Levels of Ion-Implanted Germanium in Silicon Measured by Schottky Contact Techniques, Appl. Phys. Lett. 23, 31$33(1973)$.

49. Shannon, J. M., Increasing the Effective Height of a Schottky Barrier Using Low-Energy Ion Implantation, Appl. Phys. Lett. 25, 75-77 (1974).

50. Shannon, J. M., Control of Schottky Barrier Height Using Highly Doped Surface Layers, Solid-State Electron. 19, 537-543 (1976).

51. Nicollian, E. H., Schwarz, B., Coleman, D. J., Jr., Ryker, R. M., and Brews, J. R., Influence of a Thin Oxide Between Metal and Semiconductor on Schottky Diode Behavior, J. Vac. Sci. Technol. 13, 1047-1055 (1976).

52. Shannon, J. M., I-V Impurity Profiling with a Schottky Barrier, Appl. Phys. Lett. 31, 707-709 (1977).

53. van der Ziel, A., Metal p-n Schottky Barrier Diodes, Solid-State Electron. 20, 269-272 (1977).

54. Borrego, J. M., Gutmann, R. J., and Ashok, S., Richardson Constant of Al-Au-GaAs Schottky Barrier Diodes, Appl. Phys. Lett. 30, 169-172 $(1977)$.

55. Muret, P., and Deneuville, A., Type II Localized Interface States and Silicon Surface Preparation for Ni, Pt, Al/Si Schottky Diodes, Appl. Phys. Lett. 32, 256-258 (1978). 
56. van Otterloo, J. D., and Gerritsen, L. J., The Accuracy of SchottkyBarrier-Height Measurements on Clean Cleaved Silicon, J. Appl. Phys. 49, 723-729 (1978).

57. Andersen, J. U., Davies, J. A., Nielsen, K. O., and Andersen, S. L., An Experimental Study of the Orientation of $(p, \gamma)$ Yields in Monocrystalline Aluminum, Nucl. Instmum. Methods 38, 210-215 (1965).

58. Nishi, H., Inada, T., Sakurai, T., Kaneda, T., Hisatsugu, T., and Furuya, T., Uniform Doping of Channeled-Ion Implantation, J. Appl. Phys. 49, 608-613 (1978).

59. Schulz, F., Wittmaack, K., and Maul, J., Implication in the Use of Secondary Ion Mass Spectrometry to Investigate Impurity Concentration Profiles in Solids, Radiat. Eff. 18, 211-215 (1973).

60. Evans, C. A., Jr., Secondary Ion Mass Analysis: A Technique for Three Dimensional Characterization, Anal. Chem. 44, 67A-80A (1972).

61. Jamba, D. M., Secondary Particle Collection in Ion Implantation Dose Measurement, Rev. Sci. Instmum. 49, 634-638, 1978; Jamba, D. M., Semiconductor Measurement Technology: Some Aspects of Dose Measurement for Accurate Ion Implantation, NBS Spec. Publ. 400-39 (September 1977).

62. Wilson, R. G., and Comas, J., Atom and Carrier Depth Distributions of Be Implanted in Si, J. Appl. Phys. (to be published).

63. Kalbitzer, S., and Oetzmann, H., Ranges and Range Theories, Proc. Ion Beam Modification of Materials Conf., September 4-8, 1978, Budapest, Hungary, pp. 3-34. 
NBS.114A (REV. 2-8C)

U.S. DEPT. OF COMM

BIBLIOGRAPHIC DATA

SHEET (See in structions)

1. PUBLICATION OR

REPORT NO.

NBS SP 400-71

2. Performing Organ. Report No. 3. Publication Date

February 1982

4. TITLE AND SUBTITLE

Semiconductor Measurement Technology: Differential Capacitance-

Voltage Profiling of Schottky Barrier Diodes for Measuring

Implanted Depth Distributions in Silicon

5. $A \cup T H O R(S)$

R.G. Wilson and D.M. Jamba

6. PERFORMING ORGANIZATION (If joint or other than NBS, see instructions)

7. Contract/Grant No.

Hughes Research Laboratories

$5-35891$

3011 Malibu Canyon Road

8. Type of Report \& Period Covered

Malibu, CA 90265

9. SPONSORING ORGANIZATION NAME AND COMPLETE ADDRESS (Street. City. State, ZIP)

Defense Advanced Research Projects Agency

1400 Wilson Boulevard

Arlington, VA 22209

10. SUPPLEMENTARY NOTES

Library of Congress Catalog Card Number: 81-600162

[D Document describes a computer program; SF-185. FIPS Software Summary, is attached.

11. ABSTRACT (A 200-word or less foctual summary of most significant information. If document includes a significant tibliography or literoture survey. mention it here)

This report discusses experimental and analytical aspects of differential capacitance-voltage profiling of ion-implanted carrier depth distributions using reverse-biased schottky barrier diodes and the associated accuracies, experimental errors, and ranges of applicability.

12. KEY WORDS (Six to twelve entries; alphabetical order: capitalize only proper names; and seporate key words by semicolons) automatic $C-V$ profiler analyses; carrier depth distributions; differential capacitancevoltage profiling; ion implantation; ranges of application and limitations; Schottky barrier diodes; SIMS and $\mathrm{C}-\mathrm{V}$ profile comparisons

13. AVAILABILITY

X Unlimited

For Official Distribution. Do Not Release to NTIS

Order From Superintendent of Documents, U.S. Government Printing Office, Washington, D C 20402.

14. NO. OF PRINTED PAGES

58

X Order From National Technical Information Service (NTIS), Springfield, VA 22161

15. Price 



\section{Announcement of Semiconductor Measurement Technology List of Publications 72 - 1962-1981}

Elaine C. Cohen

Information Assistant

Semiconductor Materials and Processes Division

National Bureau of Standards

Bldg. 225, Room A305

Washington, DC 20234

Dear Mrs. Cohen:

Please send a copy of your latest "Semiconductor Measurement Technology, List of Publications 72."

Name

Company

Address

City

State

ZIP Code 





\section{NBS TECHNICAL PUBLICATIONS}

\section{PERIODICALS}

JOURNAL OF RESEARCH-The Journal of Research of the National Bureau of Standards reports NBS research and development in those disciplines of the physical and engineering sciences in which the Bureau is active. These include physics, chemistry, engineering, mathematics, and computer sciences. Papers cover a broad range of subjects, with major emphasis on measurement methodology and the basic technology underlying standardization. Also included from time to time are survey articles on topics closely related to the Bureau's technical and scientific programs. As a special service to subscribers each issue contains complete citations to all recent Bureau publications in both NBS and non\B. media. Issued six tımes a year. Annual subscription; domesuc S18: foreign \$22.50. Single cupy \$4.25 domestic: $\$ 5.35$ loreign. NOTE: The Journal was formerly published in two sections: Section A "Physics and Chemistry" and Section B "Mathematical Sciences."

DIMENSIONS/NBS-This monthly magazine is published to inform scientists, engineers, business and industry leaders, teachers, students, and consumers of the latest advances in science and technology, with primary emphasis on work at NBS. The magazine hıghlights and reviews such issues as energy research, fire protectıon, building technology, metric conversion, pollution abatement, health and safety, and consumer product performance. In addition, it reports the results of Bureau programs in measurement standards and techniques, properties of matter and materials, engineering standards and services, instrumentation, and automatic data processing. Annual subscription: domestic \$11; foreign $\$ 13.75$

\section{NONPERIODICALS}

Monographs-Major contributions to the technical literature on various subjects related to the Bureau's scientific and technical activitıes.

Handbooks-Recommended codes of engineering and industrial practice (including safety codes) developed in cosperation with interested industries, professional organizations, and regulatory bodies.

Special Publications-Include proceedings of conferences sponsored by NBS, NBS annual reports, and other special publications approprıate to this grouping such as wall charts, pocket cards, and biblıographies.

Applied Mathematics Series-Mathematical tables, manuals, and studies of special interest to physicists, engineers, chemists, bıologists, mathematicians, computer programmers, and others engaged in scientific and technical work

National Standard Reference Data Series-Provides quantitative data on the physical and chemical properties of materials, compiled from the world's literature and critically evaluated Developed under a worldwide program coordinated by NBS under the authority of the National Standard Data Act (Public Law 90-396)
NOTE: The principal publication outlet for the foregoing data is the Journal of Physical and Chemical Reference Data (JPCRD) published quarterly for NBS by the American Chemical Society (ACS) and the American Institute of Physics (AIP). Subscriptions, reprints, and supplements available from ACS, I155 Sixteenth St. NW, Washington, DC 20056

Building Science Series-Disseminates technical information developed at the Bureau on building materials, components, systems, and whole structures. The series presents research results, test methods, and performance criteria related to the structural and environmental functions and the durability and safety characteristics of building elements and systems.

Technical Notes-Studies or reports which are complete in themselves but restrictive in their treatment of a subject. Analogous to monographs but not so comprehensive in scope or definitive in treatment of the subject area. Often serve as a vehicle for final reports of work performed at NBS under the sponsorship of other government agencies.

Voluntary Product Standards-Developed under procedures published by the Department of Commerce in Part 10. Title 15, of the Code of Federal Regulations. The standards establish nationally recognized requirements for products, and provide all concerned interests with a basis for common understanding of the characteristics of the products. NBS administers this program as a supplement to the activities of the private sector standardizing organizations.

Consumer Information Series-Practical information, based on NBS research and experience, covering areas of interest to the consumer. Easily understandable language and illustrations provide useful background knowledge for shopping in today's technological marketplace.

Order the above NBS publications from: Superiniendent of Documents, Government Printing Office, Washington, DC 20402.

Order the following NBS publications-FIPS and NBSIR's-from the National Technical Information Services, Springfield, VA 22161.

Federal Information Processing Standards Publications (FIPS PUB)-Publications in this series collectively constitute the Federal Information Processing Standards Register. The Register serves as the official source of information in the Federal Government regarding standards issued by NBS pursuant to the Federal Property and Administrative Services Act of 1949 as amended, Public Law 89-306 (79 Stat. 1127), and as implemented by Executive Order 11717 (38 FR 12315, dated May 11, 1973) and Part 6 of Title 15 CFR (Code of Federal Regulations).

NBS Interagency Reports (NBSIR)-A special series of interim or final reports on work performed by NBS for outside sponsors (both government and non-government). In general, initial distribution is handled by the sponsor; public distribution is by the National Technical Information Services, Springfield, VA 22161, in paper copy or microfiche form. 


\section{U.S. DEPARTMENT OF COMMERCE}

National Bureau of Standards

Washington, DC 20234

OFFICIAL BUSINESS

Penalty for Private Use, $\$ 300$
PDSTAGE AND FEES PAID

U.S. DEPARTMENT DF CDMMERCE COM -215

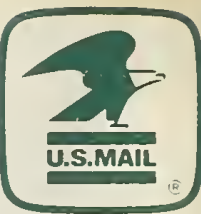

THIRD CLASS 